\title{
Chemical "Diversity" of Chromatin Through Histone Variants and Histone Modifications
}

\author{
Cindy Law $・$ Peter Cheung $\cdot$ Keyur Adhvaryu
}

Published online: 11 February 2015

(C) Springer International Publishing AG 2015

\begin{abstract}
The eukaryotic genome is highly complex and compartmentalized into distinct physical and functional domains. Although the majority of genomic DNA is wrapped around histone proteins in the same manner to form repeating units of nucleosomes, the use of distinct histone variants and the myriad of posttranslational modifications (PTMs) on different histones and amino acid residues create great diversity among these nucleosomes. In this review, we summarize some of the most recent findings in the histone variant and PTM fields and update the readers on our current understanding of various histone-related pathways. Furthermore, we discuss how homotypic or heterotypic deposition of histone variants as well as symmetric or asymmetric histone PTMs within the nucleosome context can further expand the diversity and functionality of chromatin. Altogether, this review highlights the complexity of chromatin composition and organization and their regulatory functions within the eukaryotic genome.
\end{abstract}

Keywords Chromatin · Histone variants $\cdot$ Covalent histone modifications $\cdot$ Nucleosomes $\cdot$ Homotypic $\cdot$ Heterotypic nucleosomes

\section{Introduction: Chromatin Organization and Diversity}

In eukaryotic organisms, the genome is organized through the interaction of DNA and histone proteins to form chromatin.

This article is part of the Topical Collection on Epigenetics

C. Law

Department of Medical Biophysics, University of Toronto,

Toronto, Canada

P. Cheung $(\bowtie) \cdot \mathrm{K}$. Adhvaryu $(\bowtie)$

Department of Biology, York University, Toronto, Canada

e-mail: pmcheung@yorku.ca

e-mail: keyur@yorku.ca
This organization not only allows efficient compaction of the genetic material, but also enables compartmentalization of the genome into distinct structural and functional domains. For example, differential compaction of chromatin results in the formation of euchromatic (more accessible) and heterochromatic (less accessible) states. In general, euchromatin has an open and decondensed structure and is enriched for actively transcribed genes. In contrast, heterochromatin refers to condensed regions of the genome associated with nontranscribed or silenced genes. Heterochromatin can be further divided into constitutive or facultative forms with the former associated with stably silenced DNA regions such as short repetitive sequences, and the latter associated with inducible genes that are in the repressed state. In addition to these functional domains, the eukaryotic genome also has defined structures such as the nucleoli, centromeres, and telomeres. Altogether, the eukaryotic genome is highly organized and compartmentalized based on structurally and chemically distinct types of chromatin.

The basic repeating unit of chromatin is the nucleosome, each of which comprises $147 \mathrm{bp}$ of DNA wrapped around two copies each of the four core histones, H2A, H2B, H3, and H4 [1]. Given that all nucleosomes have the same architecture, how are the various types of chromatin generated? The answer lies in two general methods of modifying the basic nucleosome. First, eukaryotic cells express a collection of nonallelic isoforms of the core histones referred to as histone variants that replace their canonical counterparts at specific locations within the genome. These replacement histones have individual or stretches of unique amino acids that differ from the canonical histones, and therefore, incorporation of these variants will generate physically and compositionally distinct nucleosomes. Second, histones are subjected to a variety of posttranslational modifications (PTMs) that are added to specific residues on different histones. The myriad of possible combinations of these site-specific PTMs on both core and histone 
variants further create a wide range of chemically and functionally distinct nucleosomes and chromatin.

Chromatin and histone biology have been intensely studied over the past 15-20 years, and a wealth of knowledge on those subjects has accumulated over that time. Many of those studies help define how these chromatin modifications correlate with or molecularly determine the types of genomic domains mentioned earlier. Interested readers can read some of the many excellent reviews written over the years on these topics (see [2-7]). For this review, we will focus on some of the recent papers (published in the last 3-5 years) on both histone variants and PTMs. Moreover, along the theme of chromatin diversity, we further highlight how additional diversity can be generated through homotypic versus heterotypic incorporation of histone variants and also symmetric versus asymmetric deposition of histone PTMs. Altogether, these mechanisms generate highly complex and diverse varieties of chromatin found within the eukaryotic genome.

\section{Histone Variants}

As the gatekeepers of the genome, histone proteins are among the most conserved proteins in all eukaryotes. Core or canonical histones are encoded by multiple copies of genes that do not contain introns and are transcribed into messenger RNAs (mRNAs) that contain special 3' stemloops instead of the usual poly-A tails. The conserved stemloop structure at the 3' ends of core histone mRNAs restricts their expression to $\mathrm{S}$ phase and, thus, ensures a supply of new histones for partnering with the newly synthesized DNA [8].

In addition to specific amino acid differences, histone variants also differ from core histones in that they are encoded by intron-containing single-copy genes, and their mRNAs are polyadenylated at the $3^{\prime}$ ends. These variant forms of histones are expressed throughout the cell cycle and incorporated at defined genomic locations. All core histones have variant isoforms, with some specifically expressed in certain cell types or organisms. Histone variants provide physical and functional diversity to the nucleosome, and they are involved in many cellular processes such as transcriptional regulation, RNA splicing, DNA replication, recombination, and repair [3].

\section{The Diverse Roles of Histone Variants}

Among the histone variants, the $\mathrm{H} 3$ and $\mathrm{H} 2 \mathrm{~A}$ families are ubiquitously expressed and most abundant in eukaryotic cells. For the H3 family, there are four replacement $\mathrm{H} 3$ variants in addition to the canonical H3.1 and H3.2. This group includes the centromere-specific variant, CENP-A; two testis-specific variants, $\mathrm{H} 3 \mathrm{t}$ and $\mathrm{H} 3.5$; and H3.3. CENP-A is found at centromeres and is essential for kinetochore formation and chromosome segregation. $\mathrm{H} 3 \mathrm{t}$ and $\mathrm{H} 3.5$ are specifically found in the testes; the former has four additional amino acids compared to $\mathrm{H} 3.1$ and the latter has a $\sim 96 \%$ sequence identity with H3.3. Finally, among all the $\mathrm{H} 3$ replacement variants, $\mathrm{H} 3.3$ is the most studied and best known for its association with active transcription (reviewed in [8]). More recently, species-specific $\mathrm{H} 3$ variants, such as H3.X and H3.Y, have also been found in some primates, but their functional roles are currently unclear [9]. Histone H2A has the largest family of variants including H2A.X, H2A.Z, macroH2A, and H2A.B (previously known as H2A.Bbd). Whereas H2A.Z and H2A.X are conserved throughout evolution, the other two members, macroH2A and H2A.B, are only found in vertebrates and mammals, respectively (reviewed in [8]). Given that these two histone variant families are the most studied, this review will focus on some of the newest findings on H3.3 and other $\mathrm{H} 2 \mathrm{~A}$ variants.

\section{H3.3 - the Transcription-Associated Variant}

H3.3 is the predominant form of $\mathrm{H} 3$ expressed outside of $\mathrm{S}$ phase. Although this variant differs from H3.2 and H3.1 by four and five amino acids, respectively, it has specialized functions compared to the canonical H3. The difference in sequence at residues $87-90$ between canonical $\mathrm{H} 3$ and $\mathrm{H} 3.3$ is responsible for the replication-independent deposition of H3.3. In mammals, there are two separate genes (H3.3A and $H 3.3 B$ ) that encode identical H3.3 proteins [10].

Genome-wide analyses found that H3.3 is mostly enriched at actively transcribed genes marked by K4-methylated H3 and RNA Pol II. In addition, knockdown of H3.3 or HIRA, the main H3.3 chaperone, inhibited induction of H3.3-target genes, indicating that $\mathrm{H} 3.3$ is required for gene activation [11, 12]. More recent studies have found $\mathrm{H} 3.3$ at silent chromatin loci as well, including heterochromatic regions such as ribosomal DNA (rDNA) repeats in Drosophila, and telomeres and pericentric heterochromatin in mouse embryonic stem cells (ESCs) and mouse embryonic fibroblasts (MEFs), respectively [10]. Functional studies further suggested that H3.3 deposition is required for gene repression at telomeres [13]. Apart from transcriptional regulation, deposition of $\mathrm{H} 3.3$ also affects chromatin accessibility. For example, H3.3 and the chromatin remodeling complex FACT were found to be enriched at $\mathrm{V}(\mathrm{D}) \mathrm{J}$ regions of the genome in B cells, and H3.3 was suggested to contribute to the somatic hypermutation (SHM) process that generates the variety of antibodies in the immune system [14]. In this process, H3.3 may be mediating the rapid histone exchange required for transcription of SHM target genes and also for regulating accessibility of DNA by the cleavage enzymes. H3.3 also has a role in maintaining chromatin accessibility at enhancers by creating an open chromatin structure, and H3.3 nucleosomes undergo rapid turnover at 
enhancers as well as promoters $[15,16 \bullet]$. H3.3 has been found at the chromatin boundary elements in Drosophila cells and implicated to maintain heterochromatin-euchromatin boundaries and to prevent spreading of heterochromatin silencing [17]. Finally, H3.3 has been found to function as a placeholder for CENP-A at centromeres during S phase [18]. Altogether, while H3.3 deposition at gene bodies is coupled to transcription, H3.3 incorporation can also be found at other active or silent regions in the genome.

\section{H3.3 Deposition}

The deposition of $\mathrm{H} 3.3$ at different genomic regions is mediated by distinct chaperones and remodeling complexes. Previous studies have already established that H3.3 is deposited into euchromatin by the chaperone HIRA, whereas H3.3 incorporation at telomeric and pericentric heterochromatin is mediated by the DAXX-ATRX complex. In spite of the small amino acid differences, these H3.3 chaperones are able to distinguish between canonical and variant $\mathrm{H} 3 \mathrm{~s}$. For example, recent crystallography studies revealed that the histonebinding domain of DAXX contains a small hydrophobic pocket that accommodates hydrophobic Ala87 in H3.3 and also a polar binding environment that prefers Gly90 in H3.3, but disfavors the hydrophobic Met90 residue in H3.1 [19, 20•, 21]. Another study found that DEK, another H3.3-associated protein, is required for proper loading of ATRX and H3.3 at telomeres, and functions to regulate differential HIRA- and DAXX/ATRX-dependent deposition of H3.3 [22]. Finally, additional studies have shown that H3.3 is targeted to PML bodies in a DAXX-dependent manner [23, 24]. Taken together, these studies show the importance of histone chaperones in regulating targeted deposition of H3.3 and determining the steady-state levels of this variant at various regions of the genome.

\section{H3.3's Roles in Epigenome Reprogramming and Embryonic Development}

H3.3 was first proposed to be a key player in epigenome reprogramming during somatic cell nuclear transfer (SCNT) by $\mathrm{Ng}$ and Gurdon [25]. The authors found that expression of some lineage-specific genes persists when donor nuclei were transplanted into enucleated Xenopus ooctyes during SCNT reprogramming. They called this phenomenon epigenetic memory and found that it can persist for over 24 mitotic divisions in the absence of transcription and even after two rounds of nuclear transfer. The persistence of this epigenetic memory correlated with the presence of $\mathrm{H} 3.3$ at the lineage-specific genes, and alterations of the overall H3.3 levels affected the epigenetic memory of those genes. Since that study, the role of
H3.3 in epigenetic reprogramming has been an area of great interest (reviewed in [26]). For example, studies in Xenopus showed that HIRA-dependent $\mathrm{H} 3.3$ deposition is required for the transition of a somatic cell-type transcription to an oocytetype transcription profile in SCNT [27]. Using small interfering RNA (siRNA) to knockdown H3.3 expression in mouse SCNT experiments, Wen et al. found that maternal H3.3, but not the H3.3 in the donor nuclei, was critical for successful reprogramming and reactivation of pluripotent genes in the reprogrammed nuclei [28•]. Finally, they found that the original H3.3 on the donor genome was gradually replaced by maternal $\mathrm{H} 3.3$ present in the recipient oocyte and that eviction of donor H3.3 is dependent on the incorporation of maternal H3. 3 into the donor cell chromatin.

In the context of embryonic development, recent discoveries showed that H3.3 is involved in multiple steps of this process, including fertilization, preimplantation of embryos, and the regulation of developmental genes [28•, 29-33]. Loss of H3.3 through genetic disruption resulted in infertility and defects in spermatogenesis in mice $[34,35]$. During normal spermatogenesis, histones are replaced by protamines in the mature sperm, but small amounts of H3.3 are retained at regions of the genome important for zygotic development. Mice that harbor targeted disruption of the $H 3 f 3 b$ gene not only have disrupted expression of spermatogenesis-related genes, but also have defects in the histone-to-protamine replacement during spermatogenesis [35]. H3.3 also has a role in maintaining proper chromatin structure during the initial stages of embryonic development, and loss of H3.3 often leads to missegregation of chromosomes [33, 34]. In mouse ESCs, $\mathrm{H} 3.3$ is required for proper establishment of $\mathrm{H} 3 \mathrm{~K} 27 \mathrm{me} 3$ at the promoters of developmentally regulated genes. It is also thought to be responsible for the chromatin conformation changes during embryo development, as well as for the establishment/maintenance of PTMs involved in the regulation of developmental genes [33, 34, 36]. These and other studies showed that H3.3 is an essential component of development and important for establishing chromatin structures and epigenetic states in this process $[37,38]$.

\section{H3.3 Mutations and Oncogenesis}

Recently, the first histone mutation directly linked to cancer development was discovered in the H3.3-coding H3F3A gene. Mutations of this gene were found in high frequencies in pediatric glioblastomas, and the mutations specifically map to single codon changes that lead to H3.3 K27M or G34R/V substitutions [39, 40]. Gliomas harboring H3.3 mutations also exhibited a lower overall amount of $\mathrm{H} 3 \mathrm{~K} 27 \mathrm{me} 3$ in those cells. Biochemical analyses showed that K27M nucleosomes inhibited methylation of $\mathrm{K} 27$ on the same and nearby nucleosomes and caused an increase in K27Ac [41 •, 42]. Finally, 
Lewis et al. found that a K27M peptide was able to inhibit the methyltransferase activity of Ezh2, and thus provided a plausible mechanism of how H3.3 K27M mutation could alter global H3K27me3 levels through the inhibition of the Ezh2/PRC2 histone methyltransferase activity. The mechanism through which the $\mathrm{H} 3.3 \mathrm{G} 34 \mathrm{R} / \mathrm{V}$ mutations contribute to gliomagenesis is less clear, but preliminary studies found that this mutation may alter overall H3K36me3 levels in glioma cells [39].

\section{H2A.Z - the Essential H2A Variant}

Another well-studied histone variant is H2A.Z, a variant that shares $\sim 60 \%$ sequence identity with the canonical H2A. H2A.Z is an essential histone variant in complex eukaryotes and has been implicated in a variety of biological processes (reviewed in [8]). Similar to H3.3, H2A.Z is also encoded by two different genes (H2A.Z.1 and H2A.Z.2) that make distinct isoforms that differ by three amino acids. In addition, the H2A.Z.2 transcript can be alternatively spliced to produce an additional isoform, H2A.Z.2.2, which lacks the C-terminal docking domain and forms nucleosomes that are highly unstable $[43,44 \bullet]$. H2A.Z has long been associated with transcriptional regulation [45], and ChIP-chip and ChIPsequencing data support this notion as they showed that H2A.Z is enriched at the transcription start sites of many genes. In this context, the incorporation of H2A.Z maintains chromatin at a poised (open but transcriptionally silenced) state that can be further modified by different PTMs to facilitate transcriptional activation or repression (reviewed in [46]). In addition to transcriptional regulation, H2A.Z has also been linked to diverse functions such as antagonizing heterochromatin spreading [47], centromeric functions during mitosis $[48,49]$, sister chromatid cohesion [50], as well as DNA damage repair [51, 52]. Although at first glance these diverse functions may seem unrelated, they may be connected through H2A.Z's effect on chromatin architecture and stability.

\section{H2A.Z Localization and Deposition}

Early studies found that genomic deposition of H2A.Z is mediated by either the Swr1 or p400 complexes in yeast and mammalian cells. More recently, ANP32E was identified as another H2A.Z-specific chaperone that removes H2A.Z from enhancer regions in mammalian cells $[53,54 \bullet]$. The Swr1 complex binds to acetylated histones in general to preferentially deposit H2A.Z at acetylated regions of the genome [55]. However, recent studies by Ranjan et al. showed that recognition of a nucleosome-free region by the Swr1 complex was more efficient for its targeting to DNA than recognition of acetylated chromatin [56]. The link between histone acetylation and
SWR1 targeting may also depend on the site of acetylation since hyperacetylation of $\mathrm{H} 3 \mathrm{~K} 56$ was found to antagonize binding of Swr1 complex and prevent H2A.Z deposition in yeast [57]. Finally, the acetylation status of H2A.Z itself may also be important for its retention since the chromatin remodeling complex Ino80 in yeast actively removes unacetylated H2A.Z from chromatin [58]. Therefore, the PTMs on H2A.Z as well as on other histones within the chromatin domain can affect the deposition and maintenance of this variant.

One main physical difference between H2A and H2A.Z is the presence of an extended acidic patch in the variant's Cterminal domain, which is thought to facilitate interactions between neighboring nucleosomes. The precise effect of H2A.Z's incorporation on nucleosome stability has been controversial with contrasting findings reported in the literature (reviewed in [8]). Part of the issue may be that the overall stability of H2A.Z-containing nucleosomes is also dependent on which other histone isoform, such as $\mathrm{H} 3.1$ or H3.3, is partnered with H2A.Z (further discussed later in this review). In addition, whether H2A.Z is present in a homotypic or heterotypic fashion also affects the overall stability of the H2A.Zcontaining nucleosome (see "Conclusions and Perspectives" section for more details). Although H2A.Z may physically stabilize the structure of mononucleosomes, it is also found to resist higher order chromatin structures, which is consistent with a role for H2A.Z in poising genes for activation and resisting permanent silencing (reviewed in [59]). In yeast, H2A.Z is enriched at the transcription start site (TSS) of inducible genes and acetylation of H2A.Z correlates with gene activation $[60,61]$. Acetylation of H2A.Z may in turn recruit specific transcription factors [62] and/or histone-modifying enzymes. Finally, consistent with H2A.Z functioning to poise the underlying chromatin structure for downstream regulatory steps, Yang et al. found that gene reactivation by DNA demethylation requires SRCAP-mediated deposition of H2A.Z [63]. Therefore, incorporation of H2A.Z may be a prerequisite for the activation as well as derepression of specific genes.

\section{H2A.Z's Involvement in Cellular Differentiation and Development}

Recent studies have shown that not only is H2A.Z involved in the transcriptional activation of genes, but it may also have an essential role in maintaining the epigenetic state of ESCs. For example, H2A.Z has been shown to be required for the differentiation of ESCs as well as other cell types [64, 65•, 66]. H2A.Z is also critical for the development of various organisms including mice, Xenopus, Tetrahymena, Drosophila, and Caenorhabditis elegans [8], and it is responsible for the maintenance of cell fate in C. elegans [67]. The mechanistic details of how H2A.Z regulates repression of developmental genes in ESCs and their subsequent activation 
upon differentiation are still unclear. However, the PTMs of H2A.Z may be important in these processes since acetylation of this variant is linked to transcriptional activation, whereas monoubiquitylation of H2A.Z is linked to silenced genes [46]. More recently, dually modified H2A.Z (both acetylated and ubiquitylated) has been found and shown to be associated with bivalent genes in mouse ESCs [68•]. While the specific significance of this dually modified H2A.Z is still unclear, H2A.Z is found to work in combination with other transcription factors to mediate nucleosome depletion during ESC differentiation [69]. Therefore, these findings are again consistent with H2A.Z having a chromatin poising function, and that it may engage both transcriptional activating and silencing mechanisms at the same time to allow for controlled and rapid activation when induced.

\section{Partnering of H2A.Z and H3.3 at DNA Regulatory Regions}

Many studies have drawn parallels between H2A.Z and H3.3. Both variants are localized to promoters and enhancers, and both are linked to transcriptional activation. In vitro studies showed that the combination of these two variant produces labile and unstable nucleosomes [70]. In vivo, this combination is thought to mark "nucleosome-free" regions at promoters [71]. Studies by Chen et al. have provided a clearer mechanistic picture of the interplay between these two variants during gene activation [16॰]. They proposed that the main role of H2A.Z is for chromatin compaction and poising genes for activation, whereas H3.3 incorporation prevents higher order chromatin folding and promotes gene activation. Moreover, they delineated a sequential H3.3-dependent recruitment of H2A.Z mechanism to maintain chromatin compaction and poising of transcription at the same time. This example suggests how two different variants can work together to provide further functional diversity to nucleosomes.

In addition to the mechanistic studies that connect H2A.Z to transcriptional regulation, other recent studies have implicated H2A.Z in cancer biology, in part through its role in regulating expression of cell cycle-related genes [72-74]. H2A.Z has been shown to be upregulated in different cancer types, whereas the knockdown of H2A.Z expression results in a decrease in proliferation of cancer cells $[72,75]$. These discoveries underscore the importance of H2A.Z in transcriptional regulation and other chromatin-regulated processes, and that dysregulation of H2A.Z expression could lead to disease-causing consequences.

\section{H2A.B Localization and Impact on Chromatin Structure}

H2A.B, previously known as H2A.Bbd (see [76]), is the smallest and most divergent $\mathrm{H} 2 \mathrm{~A}$ variant $[77,78]$. This variant was initially found to be excluded from the Barr body (the inactive $\mathrm{X}$ chromosome in female cells) and, thus, was named as Barr body-deficient (Bbd). The X chromosome inactivation process is part of the dosage compensation mechanism that balances the expression of X-linked genes in males and female cells. Given its exclusion from the silenced inactive X chromosome, H2A.B is thought to be involved in transcriptional activation [8].

Structural analysis supports the predicted positive role of H2A.B in transcription regulation. H2A.B nucleosomal arrays resist chromatin compaction and are more accessible to DNases [8]. This is likely due to the missing acidic patch on H2A.B, which on the other H2A family members is important for the folding of chromatin into the $30-\mathrm{nm}$ fiber. H2A.B nucleosomes are unstable and are wrapped around by a shorter than normal amount of DNA per nucleosome ( $\sim 130 \mathrm{bp}$ compared to the normal $147 \mathrm{bp}$ ). It is of interest to note that H2A.B only contains one lysine compared to the 14 lysine residues in H2A, which means that H2A.B lacks most of the potentially modified residues on $\mathrm{H} 2 \mathrm{~A}$. Previous structural analysis on H2A.B nucleosomes has shown that the DNA segments at the entry and exit sites are flexible and detached [79]. Recent $\mathrm{X}$-ray scattering analysis has also supported a more open H2A.B nucleosomal structure, whereby the H2A.B octasome is more extended as compared to the $\mathrm{H} 2 \mathrm{~A}$ octasome [80 ${ }^{\bullet}$. In addition, small-angle neutron scattering analysis comparing the H2A.B nucleosome structure with canonical H2A revealed that while the DNA is more loosely attached in the H2A.B nucleosome, the histone tails are more tightly associated with the histone core within the nucleosome [81]. Altogether, these data showed that H2A.B incorporation results in a distinct nucleosome structure whereby the interactions with DNA segments are weaker and, thus, result in a less stable nucleosome.

\section{H2A.B's Cellular Functions}

Given the unstable nature of H2A.B nucleosomes, a recent study proposed that H2A.B may function to form "intermediate" nucleosomes that represent a transitional state during the chromatin changes associated with different cellular processes [80•]. In vitro analyses showed that H2A.B form either octasomes or hexasomes with shorter DNA fragments, such as $124 \mathrm{bp}$ of DNA, whereas H2A can only form hexasomes with the same length of DNA. Having found that H2A.B nucleosomes can form rapidly and transiently over shorter DNA fragments, Arimura et al. proposed that H2A.B can act as a histone placeholder to transiently associate with and stabilize the DNA exposed during processes such as DNA replication, repair, and transcription. H2A.B has recently been found at sites of DNA replication and repair as well as at the TSS of genes activated at specific stages of spermatogenesis 
in mice [82-84]. Also supporting H2A.B having a role in transcriptional activation, a recent study that examined the transcriptome of H2A.B knockdown cells found a widespread downregulation of gene transcription in those cells [83]. Moreover, their data also showed disruption of mRNA splicing in the H2A.B knockdown cells, suggesting that this variant is required for proper mRNA processing. Indeed, H2A.B enriched chromatin is associated with splicing factors and replisome [82]; however, whether H2A.B has a direct function in RNA splicing and transcriptional activation or whether it has an indirect effect on this process due to its effect on chromatin stability is currently unknown.

\section{MacroH2A: a Repressive Histone Variant}

MacroH2A is a histone $\mathrm{H} 2 \mathrm{~A}$ variant best known for its role in gene repression. Whereas H2A.B is absent on the inactive $\mathrm{X}$ chromosome, macroH2A is enriched on this chromosome and found at regions of silenced heterochromatin. Two separate genes encode macroH2 $\mathrm{A} 1$ and macroH2 $\mathrm{A} 2$, respectively, and the macroH2A 1 transcript can also be alternatively spliced to produce the macroH2A1.1 and macroH2A1.2 isoforms [85]. While macroH2A1.1 can physically bind to poly-ADP-ribosylation (PAR-) moiety, the domain that mediates this binding is not present on macroH2A1.2 due to alternative splicing of the transcript. Most studies to date have focused on the more abundant macroH2A1 isoform, and so the macroH2A terminology is often used synonymously as macroH2A1.

MacroH2A is significantly divergent from canonical H2A with only a $64 \%$ sequence identity between this variant and its core counterpart. MacroH2A also contains an extended 25$\mathrm{kDa}$ nonhistone region at the $\mathrm{C}$-terminus that comprises two thirds of the protein's molecular mass (reviewed in [8]). Initial observations that macroH2A is enriched on the inactive $\mathrm{X}$ chromosome led to the hypothesis that this variant is involved in the formation of heterochromatin. Further studies have shown that this variant has repressive functions at other genomic regions such as imprinted genes, senescence-associated heterochromatic foci, and autosomal genes. Therefore, macroH2A may be involved in gene silencing throughout the genome and not just at the inactive $\mathrm{X}$ chromosome. Recently, the genomic distribution of macroH2A was analyzed, and this variant was found at closed chromatin that contained repressed tissue-specific genes [86]. This repressive function may be mediated by the closed and compact nucleosome and chromatin structure that results from macroH2A incorporation [87]. Additionally, macroH2A has also been shown to recruit HDACs to promote transcriptional repression through the deacetylation of neighboring histones [88]. Most recently, Pehrson et al. have succeeded in generating macroH2A1/macroH2A2 double knockout mice [89•]. These mice developed normally but some defects were observed in growth and reproduction of the mice. Consistent with macroH2A's function in transcriptional regulation, aberrant gene expression was detected in the livers of these knockout mice.

\section{Roles of MacroH2A in Differentiation and Reprogramming}

Previous studies have suggested that macroH2A may play a role in differentiation through the regulation of developmental genes [90] and in the maintenance of epigenetic state of differentiated cells $[91,92,93 \bullet]$. Recent interests in cellular reprogramming led to the discovery that macroH $2 \mathrm{~A}$ is a barrier to the reprogramming of cells using the induced pluripotent stem cell (iPS) strategy [94]. Removal of macroH2A accelerates the induced pluripotency of cells while the overexpression of this variant restricts this process [93•]. MacroH2A may be repressing the genes responsible for pluripotency in the normal cellular differentiation context. MacroH2A has also been shown to play an important role in the development of zebrafish [90]. How macroH2A is involved in the developmental process and whether this variant is involved in the regulation of the "stemness" of a cell remains to be elucidated. Finally, recent studies have also shown that macroH2A may have a prominent role in cancer development, and its links to oncogenesis are actively being investigated [88, 95].

\section{H2A.X and DNA Damage Repair}

H2A.X is the histone H2A variant most commonly linked to DNA double strand break (DSB) repair signaling. It makes up approximately $\sim 10 \%$ of total $\mathrm{H} 2 \mathrm{~A}$ molecules in human fibroblasts [96]. H2A.X is important for the homologous recombination (HR) as well as the nonhomologous end joining (NHEJ) DSB repair mechanisms [97, 98]. The synthesis of H2A.X is partially linked to DNA synthesis, and this ensures that there are enough $\mathrm{H} 2 \mathrm{~A}$.X in proliferating as well as quiescent cells if DNA repair is required [99].

H2A.X is rapidly phosphorylated at S139 at the C-terminal tail in response to DSBs. This phosphorylated form of H2A.X, called $\gamma \mathrm{H} 2 \mathrm{~A}$.X, is one of the first chromatin responses in the DNA damage repair pathway. It is required for signal amplification and subsequent recruitment of DNA damage repair proteins to the DNA damage foci [100]. H2A.X can recruit chromatin remodeling and histone-modifying complexes, including the Ino80 complex, to participate in the DNA repair process. H2A.X phosphorylation by ATM protein or DNAdependent protein kinases is triggered by DSBs induced by ionizing radiation (IR), while phosphorylation by ATR occurs in response to DNA damage at stalled replication forks [96]. 
H2A.X phosphorylation also plays additional roles during apoptosis and necrosis. In addition to $\mathrm{S} 139, \mathrm{H} 2 \mathrm{~A}$.X is also phosphorylated at Y142. This residue is ubiquitously phosphorylated and its dephosphorylation is associated with DNA damage repair [101, 102]. A recent study showed that MCPH1, a protein associated with DNA damage response, interacts with di-phosphorylated (S139/Y142ph) H2A.X [103]. Finally, recent data showed that H2A.X S16 can also be phosphorylated, and this modification results in decreased H2A.X ubiquitylation and cell transformation [104].

\section{H2A.X and Programmed Cell Death}

H2A.X has previously been linked to apoptosis based on the increase of $\gamma \mathrm{H} 2 \mathrm{~A}$.X upon TNF-related apoptosis-inducing ligand (TRAIL)-induced apoptosis. TRAIL is a wellcharacterized proapoptotic agonist that activates a chain of caspases involved in apoptosis [105, 106]. During apoptosis, $\gamma \mathrm{H} 2 \mathrm{~A} . \mathrm{X}$ staining initially localizes to a ring formation, followed by pan-nuclear staining at later times. The initial ring marked by $\gamma \mathrm{H} 2 \mathrm{~A}$.X coincides with the peripheral heterochromatic nuclear region and colocalizes with broken DNA ends labeled by TUNEL staining. These findings suggest that, during apoptosis, DNA breaks begin at the nuclear periphery before spreading throughout the genome. In this context, DNA-PK is the primary kinase responsible for phosphorylation of H2A.X. Further analyses showed that the proteins recruited to apoptosis-induced $\gamma \mathrm{H} 2 \mathrm{~A}$.X sites were different than those enriched at DNA damage sites. Since DNA repair proteins were not fully recruited to the apoptotic ring, this suggested that normal DNA repair mechanisms are not activated during apoptosis. Also, it has been shown that caspases inactivate DNA repair proteins and dampen the DNA damage repair process. Although $\mathrm{H} 2 \mathrm{~A}$.X is primarily recognized for its role in DNA damage signaling, these new data suggest that it has additional functions in the apoptotic pathway.

\section{Histone Modifications}

In addition to incorporation of histone variants, the myriad of PTMs on different histones and sites also generate great diversity within the chromatin fibers. Common modifications include methylation, acetylation, and ubiquitylation of lysines; methylation of arginines; and phosphorylation of serines, threonines, and tyrosines. These PTMs have different effects on chromatin structure and contribute to distinct downstream functions. For example, histone acetylation in general opens up chromatin and is often linked to transcriptional activation, whereas deacetylation leads to chromatin condensation and transcriptional repression. Accordingly, euchromatin is enriched with acetylated histones, whereas heterochromatin contains mostly deacetylated or hypoacetylated histones. The functions of other modifications, such as phosphorylation, methylation, and ubiquitylation, are less easily generalized. These other modifications have been linked to both transcriptional activation and repression, and their associated functions depend on the specific sites and histones modified.

Histone modifications are proposed to form a "histone code" that influences chromatin-mediated processes [107, 108]. Although at times questioned [109-111], the histone code hypothesis nevertheless has sparked great interests in identifying site-specific modifications and characterizing their biological functions. Enzymes that establish the various modifications are often simplistically described as "writers," whereas those that remove the modifications are termed "erasers" of the histone code. Moreover, some of the sitespecific modifications act as docking sites for structurally conserved binding domains, and the proteins recruited in such modification-dependent manners are termed "readers" of the histone marks $[112,113]$. It is thought that these writers, erasers, and readers work in concert to establish and regulate histone PTM-mediated functions. Finally, histone modifications can further act in combinations to recruit or repel different binding proteins, or cross-regulate one another through complex pathways [114-116]. In this review, we will focus on some of the most recent advances in both well-known and newly discovered histone PTMs (Table 1). Given the broad and complex scope of this field and due to limited space for this review, we refer interested readers to additional reviews for further reading [114-116, 137-139].

\section{Histone Acetylation}

Histone acetylation is one of the first reported covalent histone modifications [140, 141]. In the early days, the transcriptionlinked histone acetyltransferases (HATs) identified biochemically often turned out to be known transcriptional coactivators discovered by genetics studies [142-144]. The addition of acetyl groups to lysines is thought to neutralize the overall positive charge of histones and open chromatin through decreased interactions with the negatively charged DNA [145-147]. The discovery that bromodomains bind acetylated lysines further elucidated how acetylated chromatin functions to recruit transcription-associated protein through this physical interaction [148].

While most PTMs are found on the more exposed histone tails, histone core domains can also be modified. In fact, modifications on the lateral (i.e., outer) surface of nucleosomes can directly alter their interaction with DNA and affect chromatin stability [149]. Histone H3 lysine 56 is located at the edge of the lateral surface of a nucleosome and where the DNA enters and exits the nucleosome. H3K56 acetylation (H3K56ac) was first found to be essential for chromatin assembly and then 
Table 1 Novel sites for conventional histone modifications

\begin{tabular}{|c|c|c|c|c|}
\hline Modification & Sites & Organism & Function & References \\
\hline \multirow[t]{4}{*}{ Acetylation } & H3K18 & Mammals & Resistance to pathogens & {$[117 \bullet]$} \\
\hline & H3K56 & Mammals and yeast & Transcription, repair & [118-120] \\
\hline & H3K64 & Mammals & Transcription & {$[121]$} \\
\hline & H3K112 & Mammals & Transcription & {$[122 \bullet]$} \\
\hline \multirow[t]{6}{*}{ Phosphorylation } & H3T3 & Mammals and yeast & Chromosome segregation & {$[123,124]$} \\
\hline & H3T6 & Mammals & Heterochromatin & {$[125 \bullet, 126]$} \\
\hline & H3T11 & Mammals & Heterochromatin & {$[125 \bullet]$} \\
\hline & H3T80 & Mammals & Chromosome condensation & {$[127]$} \\
\hline & $\mathrm{H} 2 \mathrm{BS} 32$ & Mammals & Transcription & [128] \\
\hline & H2BS36 & Mammals & Transcription & [129] \\
\hline \multirow[t]{2}{*}{ Methylation } & H3К56 & Mammals & Heterochromatin & {$[130]$} \\
\hline & H3K64 & Mammals & Heterochromatin & {$[131]$} \\
\hline \multirow[t]{4}{*}{ Ubiquitylation } & H2AK 15 & Mammals & DNA repair & {$[132 \bullet]$} \\
\hline & H2BK34 & Mammals & Heterochromatin & {$[133,134]$} \\
\hline & H3K23 & Mammals & Transcription & {$[135 \bullet]$} \\
\hline & H4K31 & Mammals & Transcription & [136] \\
\hline
\end{tabular}

later demonstrated to be required for transcription [150]. It is also now known that $\mathrm{H} 3 \mathrm{~K} 56 \mathrm{ac}$ regulates chromatin assembly, DNA replication, and repair [130, 151-154]. More recently, acetylation of $\mathrm{H} 3$ on lysine 122 (H3K122ac), another residue on the lateral surface of the nucleosome, by p300/CBP was found to be essential for hormone-induced transcriptional activation in mammals [122•]. Similarly, acetylation of lysine 64 (H3K64ac) by p300/CBP destabilizes the nucleosome and promotes nucleosome eviction to facilitate transcription [121].

Being a central mechanism for regulating transcription in eukaryotes, histone acetylation has been targeted by infecting pathogens for their survival and propagation. For example, the levels of $\mathrm{H} 3 \mathrm{~K} 18 \mathrm{ac}$ in mammalian cells was recently found to be modulated upon certain types of bacterial infection [117•]. Listeria monocytogenes infection causes translocation of the host's cytoplasmic SIRT2 into the nucleus, which specifically deacetylates H3K18ac at various target genes. This in turn upor downregulated the expression of a number of target genes that help the pathogen survive in mammalian cells [117•]. Indeed, inhibition of cellular SIRT2 using specific inhibitors or knockdown by siRNA interferes with Listeria infection [117•]. The exact mechanism of how this bacterium induces SIRT2 translocation is currently unknown, but it does require the cell surface Met receptor as well as the PI3K/AKT pathway. Nevertheless, this example shows how bacterial pathogens have evolved to modify the host's epigenome as part of their replication strategies.

Some of the most intriguing findings in recent years pertain to new insights linking histone acetylation and cellular metabolism. Acetyl-CoA is the universal acetylgroup donor for HATs. A major source of this cofactor comes from metabolism of fatty acids and oxidation of pyruvate in the mitochondria. In particular, the pyruvate dehydrogenase complex (PDC) is the main enzyme complex responsible for generating the mitochondrial pool of acetyl-CoA $[155,156]$. Since acetyl-CoA is highly charged and difficult to transport through membranes, the nuclear pool of this cofactor is thought to be generated by other enzymes independent of the mitochondrial metabolic pathways. In lower eukaryotes, nuclear acetyl-CoA is generated by the acetyl-CoA synthetase [157], whereas in metazoans, this process is mediated by the nuclear pool of ATPcitrate lyase (ACL) [158]. While PDC was original thought to be specifically localized in the mitochondria, recent studies found that there is also a nuclear pool of this enzyme that contributes to the acetyl-CoA used for histone acetylation [159•]. Mitochondrial PDC replenishes the nuclear PDC pool at $\mathrm{S}$ phase of cell cycle and in response to serum, growth factors, or mitochondrial stress [159•]. The connections between cellular metabolism and chromatin/epigenetic mechanisms are of high interests especially given recently discovered links between metabolism and cancer $[160,161]$.

\section{Histone Phosphorylation}

Histone phosphorylation has been linked to diverse biological functions, including chromosome condensation ( $\mathrm{H} 1$ and $\mathrm{H} 3$ phosphorylation; reviewed in $[162,163])$, transcriptional regulation (H3 phosphorylation; reviewed in [164, 165]), DNA damage repair (H2A.X phosphorylation; [97, 166, 167]), and even apoptosis (H2B phosphorylation; [168-171]). Phosphorylation adds negative charges to the modified protein, and similar to histone acetylation, phosphorylation can decrease 
the association of the modified histones with DNA. Given this property, it has always been puzzling that $\mathrm{H} 1$ and $\mathrm{H} 3$ phosphorylation are associated with chromosome compaction during mitosis and meiosis $[162,163]$. One hypothesis is that $\mathrm{H} 1$ phosphorylation may in fact open up chromatin to allow binding of proteins that drive chromatin condensation [172]. The phosphorylated residues on histones themselves can directly recruit binding proteins as in the cases of $\mathrm{H} 3 \mathrm{~S} 10$ and H2A.X S139 phosphorylation (reviewed in [173]). These two examples showed that histones act as receivers of upstream signaling pathways, and the phosphorylated sites in turn recruit binding factors to translate the upstream signal to downstream chromatin functions [164, 173, 174].

H3 serine 10 phosphorylation was first associated with chromosome condensation during mitosis, and later also with transcriptional activation [164, 165]. The mechanistic details of the former function have not been fully elucidated, but recent studies suggested that $\mathrm{H} 3 \mathrm{~S} 10 \mathrm{ph}$ mediates chromosome condensation by regulating histone H4K16 acetylation (H4K16ac) [175•]. During mitosis in yeast, H3S10ph directly recruits the deacetylase Hst2p to reduce the overall H4K16ac levels and to allow chromosome condensation [175•]. This is consistent with other studies that showed that H4K16ac is a key acetylation mark that regulates chromatin compaction [176-179].

Other recent studies have identified new sites of histone phosphorylation that correlate with mitosis. For example, phosphorylation of $\mathrm{H} 3$ threonine 3 (H3T3ph) by the haspin kinase creates a binding site that is recognized by survivin, a subunit of the chromosomal passenger complex (CPC). This recruitment step is essential for the CPC localization to the inner centromeres for proper chromosome segregation during mitosis [123]. Similarly, phosphorylation of H2AS21 (H2AS121ph) by Bub1 is read by the centromeric CPC adaptor protein shughosin [180]. Both of these phosphorylation marks, H3T3ph and H2AS121ph, often coexist and are essential for proper chromosome segregation during mitosis in fission yeast and mammals [180]. Finally, phosphorylation of $\mathrm{H} 3$ threonine 80 (H3T80ph) is also enriched on chromatin during mitosis; however, the significance and the enzymes involved are currently not known [127].

The role of histone phosphorylation in gene activation is exemplified by phosphorylation of $\mathrm{H} 3 \mathrm{~S} 10$ and $\mathrm{H} 3 \mathrm{~S} 28$ in response to signal transduction cascades (reviewed in [164, 165, 181, 182]). Earlier studies have shown functional connections between phosphorylation of these sites and subsequent acetylation on H3 or H4 [183-186]. Recent studies have now identified new connections between other signal transduction pathways and histone phosphorylation. For example, PKC- $\beta_{1}$ phosphorylates $\mathrm{H} 3$ threonine 6 , which then opposes demethylation of H3K4 by LSD1 during androgen stimulation [126]. This mark is elevated in prostate carcinomas, and inhibition of PKC- $\beta_{1}$ interferes with AR-induced cell proliferation in cell culture and cancer progression of tumor xenografts [126]. More recently, H3S10ph was also shown to interfere H3T6 phosphorylation by PKC and H3T11 phosphorylation by Chk1 [125•]. H2BS32 phosphorylation by RSK2 is important for EGF-dependent signal transduction pathway, and levels of H2BS32ph are found to be elevated in skin cancer cells [128]. Finally, in response to metabolic stress, the activated AMP kinase phosphorylates H2BS36 in promoters and transcribed regions of genes to enhance transcription of target genes, such as $p 21$ and $C p t 1$, that help the cells survive under stress conditions [129]. Histone tyrosine phosphorylation has also been linked to gene activation and transcription. H3 tyrosine 41 phosphorylation (H3Y41ph) is enriched on active promoters, distal regulatory elements, and transcribed regions of tissuespecific hematopoietic genes [187]. The JAK2 kinasemediated phosphorylation of this site causes eviction of heterochromatin protein HP1 $\alpha$ to activate transcription [188]. Similarly, H2A tyrosine 57 phosphorylation (H2AY57ph) by casein kinase 2 (CK2) enhances transcriptional elongation indirectly by limiting the H2B deubiquitylation activity of SAGA complex to support H3K4me3 and H3K79me3 [189].

In addition to the connections with signal transduction pathways that regulate cell proliferation, histone phosphorylation also plays important roles in DNA replication and repair (reviewed in [190]). Although yeast Mec1 and Tell are known to phosphorylate H2AS129 to direct DSB repair, these enzymes have now been found to also phosphorylate H2BT129, and both these phosphorylation marks are essential for the recruitment of downstream factors to DSBs [191•]. Another novel mark, H3T45ph in yeast, is catalyzed by the Cdc7 during $\mathrm{S}$ phase, and this phosphorylation site is linked to DNA replication [192]. Supporting this conclusion, loss of H3T45ph causes defects in DNA replication; however, the specific function of this modification in DNA replication remains unclear. It is noteworthy that in mammals, H3T45ph appears to be associated with varied outcomes such as apoptosis as well as cell proliferation and differentiation. H3T45ph by protein kinase $\mathrm{C}-\delta$ is associated with apoptosis and believed to alter nucleosomal structure to facilitate DNA nicking and/or fragmentation [193]. In contrast, H3T45 is phosphorylated by a different kinase, the SK6 kinase 2, in response to mitogens or induction of differentiation by TPA [194]. It remains unclear how the same modification achieves these contrasting outcomes.

Phosphorylation has also been found to affect the expression and stability of histones. For example, phosphorylation of H2B tyrosine 37 (H2BY37ph) in the upstream region of histone cluster 1 by WEE1 kinase during late $\mathrm{S}$ phase excludes binding of RNA pol II and the transcriptional coactivator NPAT and inhibits the expression of this histone gene cluster [195]. This in turn helps restrict expression of replicationcoupled histones to S phase. Another event, H3 tyrosine 99 phosphorylation (H3Y99ph) triggers the ubiquitylation and 
proteasome-mediated degradation of nonnucleosomal and excessive histone H3 [196].

Phosphorylation is a dynamic process, and the overall levels of different site-specific histone phosphorylation are maintained by the balance of various kinase and phosphatase activities. Phospho-histone-binding proteins are also important for coupling histone phosphorylation to downstream functions such as transcriptional regulation or initiation of DNA repair. Compared to histone kinases, histone phosphatases and phospho-histone-binding domains are less well studied and understood. Nevertheless, in addition to the previously identified H3S10 dephosphorylation by PP1 [197] and PP2A [198], more recent studies have identified phosphatases for H4S47ph (PP1 and Wip), H3T3ph/S10ph (mitogen activated protein kinase phosphatase 2), and H3T3ph (Repoman/PP1) [199-205]. Similarly, while earlier studies have identified several phospho-histone binders, such as specific isoforms of 14-3-3 for $\mathrm{H} 3 \mathrm{~S} 10 \mathrm{ph} / \mathrm{S} 28 \mathrm{ph}$ and MDC1 for H2A.XS129ph, more recent studies have identified survivin (H3T3ph), WDR5 (H3T11ph), and shughosin (H2AS120ph) as phospho-histone readers [173, 206-208].

\section{Histone Methylation}

Core histones are methylated at multiple lysine and arginine residues. Some of the well-studied methylation sites, including H3K4me, H3K36me, and HK79me, are enriched in euchromatin and associated with transcriptional activity. In contrast, H3K9me, H3K27me, and H4K20me are enriched in heterochromatin and associated with transcriptional repression. Methylation of arginines includes symmetric or asymmetric methylation of H3R2, H3R8, H3R17, H3R26, H4R3, and H2AR3. Whereas asymmetric methylation is often associated with active transcription, symmetric methylation can drive repression and silencing. Histone methylation has been extensively studied and covered by many excellent reviews [209-214].

Studies involving histone methylation have also enhanced our understanding of histone PTM "crosstalks," the phenomenon whereby one modification affects the establishment and/ or functional outcome of other histone modifications. For example, the "phospho/methyl switch" was first proposed to explain the functional relationship between $\mathrm{H} 3 \mathrm{~K} 9$ me and H3S10ph [215, 216]. During mitosis, H3S10 phosphorylation by Aurora B on tails bearing $\mathrm{H} 3 \mathrm{~K} 9 \mathrm{me} 3$ generates a dual H3K9me3/S10ph mark and displaces any HP1 bound to the single H3K9me3 mark [215, 216]. More recently, a similar functional relationship was discovered between modifications on $\mathrm{H} 3 \mathrm{~K} 27$ and H3S28. Studies by others, as well as from our lab, showed that the mitogen- and stress-activated MSK-1 kinase not only directly phosphorylates H3S28, but the phosphorylated H3 antagonizes H3K27me3-mediated polycomb silencing. Gehani et al. found that during differentiation, phosphorylation of H3S28 at promoters of polycomb target genes establishes a H3K27me3/S28ph dual mark that displaces binding of PRC2 and results in activation of the polycombsilenced genes [217•]. Using a different approach, we directly targeted constitutively active MSK1 to the $\alpha$-globin gene and demonstrated that $\mathrm{H} 3$ phosphorylation was sufficient to reactivate this polycomb-silenced gene in nonerythroid cells [218 ]. We further found that MSK1 not only directly phosphorylates $\mathrm{H} 3 \mathrm{~S} 28$, but it also induces acetylation of the adjacent $\mathrm{K} 27$ residue, leading to a $\mathrm{H} 3 \mathrm{~K} 27 \mathrm{ac} / \mathrm{S} 28$ ph dual mark that promotes transcription [218•]. The mechanism that directly links H3K28ph and H3K27ac is still not known, but the connection between $\mathrm{H} 3$ phosphorylation and acetylation on $\mathrm{H} 3$ and $\mathrm{H} 4$ has been documented in different studies and multiple contexts, underscoring the importance of the phosphoacetylation link in chromatin regulation [165, 183-186, 218•].

Similar to phosphorylation of H3S10 and S28, phosphorylation of H3T3 also influences binding of proteins that recognize H3K4me3. H3T3ph during mitosis by haspin kinase interrupts binding of the TFIID complex subunit TAF3 to H3K 4me 3 and reduces transcription and gene expression during mitosis [124]. Therefore, H3T3 phosphorylation by haspin kinase accomplishes two functions in mitosis: to reduce transcription by interfering with recognition of $\mathrm{H} 3 \mathrm{~K} 4 \mathrm{me} 3$ and also to generate a binding site for survivin of $\mathrm{CPC}$ to facilitate chromosome segregation [123].

Similar to acetylation, some lysines on the lateral surface of the nucleosome are also methylated. While acetylation facilitates transcription, methylation of the lysines in that region is associated with repression. For example, in mammals, methylation of $\mathrm{H} 3$ lysine 64 is enriched in the regions of heterochromatin and required for gene silencing during development [131]. Similarly, H3 lysine 56 methylation mediated by G9a/ KMT1C is associated with DNA replication through its interaction with proliferating cell nuclear antigen (PCNA) [130]. Though PCNA directly binds H3K56me1 peptides, the molecular and structural details of this interaction remain to be determined.

\section{Histone Ubiquitylation}

Covalent attachment of ubiquitin onto proteins regulates their stability, localization, and function [219-221]. While the addition of ubiquitin chains (polyubiquitylation) directs proteins to the proteasome for degradation, the addition of a single ubiquitin (monoubiquitylation) usually alters the localization and function of target proteins [222, 223]. In some cases, protein ubiquitylation can recruit proteins that contain ubiquitin-binding motifs (UBMs) that in turn mediate downstream cellular functions [224]. 
Histones are primarily subjected to monoubiquitylation, and in fact, ubiquitylated H2A was the first ubiquitylated protein identified [225]. Unlike other histone modifications that are chemical modifications (such as acetyl, phospho, and methyl groups), ubiquitin is a 76 amino acid protein, and the addition of such a bulky moiety has been predicted to affect chromatin compaction [226]. Histone H2B is monoubiquitylated at its C-terminal K120 or K123 in mammals and yeast, respectively, and as mentioned before, $\mathrm{H} 2 \mathrm{BK} 120 \mathrm{ub} / 123 \mathrm{ub}$ is required for H3K4 and K79 methylation [227-229]. H2Bub reduces chromatin compaction [230•] and recruits specific binding of proteins [231]. More recently, an in vitro study using chromatin assembled with chemically ubiquitylated H2B demonstrated that H2Bub directly stimulates Dot1L-mediated H3K79 methylation on the same nucleosome, probably by modulating the activity of Dot1L in an allosteric manner [232]. Similarly, other in vitro studies using purified yeast Set1 complex and reconstituted chromatin template have shown that $\mathrm{H} 2 \mathrm{Bub}$ alters the nucleosome to facilitate recognition of H3K 4 by the n-SET domain of Set1 [233]. Recently, H2B was found to be ubiquitylated at K34, and similar to K120/123ub, this modification enhances transcription [133, 134]. Additional ubiquitylation sites have also been found on $\mathrm{H} 3$ and $\mathrm{H} 4$, and these modifications are often associated with opening of chromatin in the context of replication and transcription. For example, ubiquitylation of $\mathrm{H} 3$ lysine 23 by Uhrf1 directs replication-coupled DNA methylation [135•], whereas ubiquitylation of histone $\mathrm{H} 4$ on lysine 31 by Cul4A enhances transcription [136].

Compared to ubiquitylated $\mathrm{H} 2 \mathrm{~B}, \mathrm{H} 3$, and $\mathrm{H} 4$, monoubiquitylated $\mathrm{H} 2 \mathrm{~A}$ is much more abundant in mammalian cells, and this modification is critical for DNA damage repair as well as transcriptional silencing via the polycomb pathway. For example, a number of proteins, including CUL-4B, RNF8, RNF168, and BRCA1, have been found to ubiquitylate mammalian H2AK119 at sites of DNA damage, which serves to open chromatin and initiate assembly of repair complexes [234-238, 239•]. Recently, H2A was found to be also monoubiquitylated at either K13 or K15 in association with DNA repair [132•]. The E3 ligase RNF168 is responsible for these ubiquitylation events at sites of DSBs, and these marks are then read by 53BP1 to direct repair by NHEJ [240•]. The direct impact of H2AK13/15ub on nucleosome structure is not yet determined.

In addition to DNA damage repair, $\mathrm{H} 2 \mathrm{~A}$ ubiquitylation also functions in transcriptional repression. For example, a recent study suggested that BRCA1-mediated H2AK119ub facilitates heterochromatin formation and contributes to BRCA1's tumor suppression function [241]. In addition, H2AK119ub is also well known for its link to H3K27me3 and being part of the polycomb-silencing pathway. Traditionally, this silencing pathway is thought to start with H3K27 methylation of the polycomb target genes by EZH2 of the PRC2 complex. This histone methylation mark is recognized by the chromodomain of the polycomb protein and recruits the PRC1 complex that includes the RING1b E3 ligase. RING1b in turn ubiquitylates H2AK119, which ultimately leads to facultative heterochromatin formation and silencing of the polycomb-regulated genes [242-246, 247•]. The H2AK119 ubiquitylation step is thought to be critical for the silencing of developmental genes important for the maintenance of stem cell identity [247•]. Recent studies have added further nuances to this accepted sequence of events in polycomb silencing. For example, it was found that PCR1-mediated H2AK119ub can by itself generate a binding site that is recognized by Jarid2-Aebp2 containing PRC2, which when recruited, methylates H3K27 [248•]. The novel implication is that H2AK119ub can also initiate polycomb silencing, or it may have a role in setting up a self-enforcing loop to maintain the continued coexistence of these two covalent modifications on nucleosomes and to sustain silencing of the polycomb target genes [248•, 249•, $250 \bullet, 251 \bullet$. These and other recent findings demonstrate that ubiquitylation influences chromatin-mediated processes in multiple ways, including opening chromatin and improving accessibility to chromatin-modifying complexes or generating binding sites for other downstream factors and complexes that drive gene repression and heterochromatin silencing.

\section{Novel Modifications}

Mass spectrometry has become a vital tool for the characterization of histones and their posttranslational modifications [252]. Advances in this technology not only helped identify new or low abundance PTMs on histones, but the development of new methods and data analysis approaches also allowed characterization of combinations of histone modifications found within the histone code [253, 254]. Some of the recently identified new modifications include proline isomerization, lysine crotonylation, lysine-5-hydroxylation, and glutamine methylation, and some newly identified sites of modifications are listed in Table 2 (see table for references). These and future new modifications discovered by proteomics studies will definitely expand the growing repertoire of chemically distinct histones and nucleosomes in eukaryotes.

\section{Conclusions and Perspectives}

As highlighted in this review, although all nucleosomes follow the same basic architectural design, selective incorporation of histone variants as well as deposition of different PTMs on distinct histone sites provides great diversity to chromatin found within the genome. Adding to the already complex combinatorial uses of variants and PTMs, it is also now recognized that even though each nucleosome contains two 
Table 2 Novel modifications, structural variations, and asymmetric nucleosomes

\begin{tabular}{|c|c|c|c|c|c|}
\hline Modification & System & Writer/enzyme & Genomic distribution & Function & References \\
\hline Lysine crotonylation & Mouse & $?$ & $\begin{array}{l}\text { Active promoters or } \\
\text { potential enhancers }\end{array}$ & $\begin{array}{l}\text { Transcription of active } \mathrm{X} \\
\text { chromosome-linked genes }\end{array}$ & {$[255]$} \\
\hline Lysyl-5-hydroxylation & Mouse & Jmjd6 & $?$ & $\begin{array}{l}\text { Opposes histone N-acetylation/ } \\
\mathrm{N} \text {-methylation }\end{array}$ & {$[256]$} \\
\hline $\begin{array}{l}\text { Glutamine methylation } \\
\text { (H2AQ105) }\end{array}$ & $\begin{array}{l}\text { Human } \\
\text { Yeast }\end{array}$ & $\begin{array}{l}\text { Fibrillarin } \\
\text { Nop1 }\end{array}$ & rDNA & Transcription by RNA Pol I & {$[257]$} \\
\hline Asymmetric methylation & $\begin{array}{l}\text { ESCs, fibroblasts, } \\
\text { cancer cells }\end{array}$ & PRC-2 complex & Promoters & $\begin{array}{l}\text { Bivalent mark poises genes for } \\
\text { rapid activation or repression }\end{array}$ & {$[258 \bullet, 259 \bullet]$} \\
\hline \multirow[t]{2}{*}{ Proline isomerization } & Yeast-H3P38 & Fpr4 & Genes & $\begin{array}{l}\text { Delays transcription by inhibiting } \\
\text { H3K36me3 }\end{array}$ & {$[260,261]$} \\
\hline & Human-H1 & Pin1 & Nucleosome linker & Promotes $\mathrm{H} 1$ retention on chromatin & {$[262]$} \\
\hline \multirow[t]{2}{*}{ Histone tail clipping } & Embryonic stem cells & Cathepsin-L & $?$ & Differentiation? & [263] \\
\hline & Yeast & Prb-1? & $?$ & Expression & {$[264,265]$} \\
\hline
\end{tabular}

copies each of the four main histone types, these pairs of histones need not be identical. More specifically, histone variants can be found within nucleosomes in either a homotypic or heterotypic fashion, and PTMs on the pairs of histones within a nucleosome can exist in either symmetric or asymmetric manner (see Fig. 1). As an example, the variant H2A.Z
Fig. 1 Three additional ways to expand the diversity of nucleosomes. Beyond the chemical diversity of histones based on different histone variants and PTMs, the way that they are added to the nucleosome can further expand the functional diversity of chromatin. For example, $(1)$ the mixing and matching of variants from different histone families, such as H2A.Z and H3.3, within the nucleosome can generate structurally and functionally distinct nucleosomes. (2) Given that each nucleosome has two copies of each of the histone family members, histone variants can be incorporated in a homotypic (e.g., H2A.Z:H2A.Z) or heterotypic (e.g., H2A:H2A.Z) fashion, which will result in functionally distinct nucleosomes. (3) Histone PTMs can be deposited in a symmetrical or asymmetrical fashion within the nucleosome. As indicated in the text, a recent study showed that the bivalent $\mathrm{H} 3 \mathrm{~K} 4 \mathrm{me} 3$ / H3K27me3 marks found in ES cells are found together within a nucleosome context, but the individual methylation marks are actually on separate $\mathrm{H} 3$ molecules within the nucleosome

\section{Designer Nucleosomes} 1) Combination of histone variants from different families

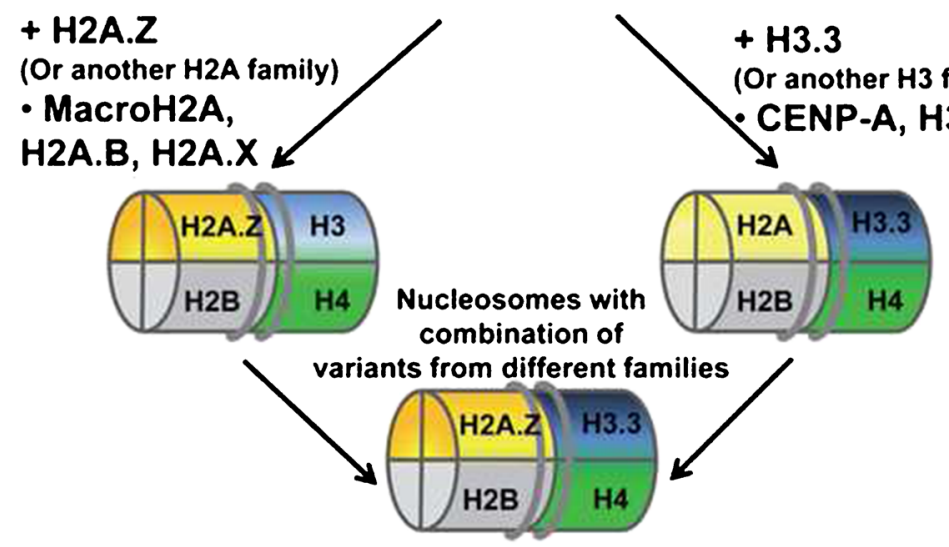

2) Choose histone variants from the same family

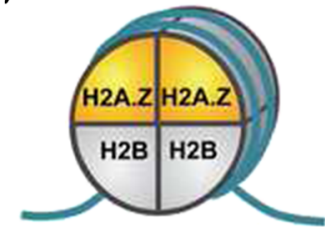

Homotypic

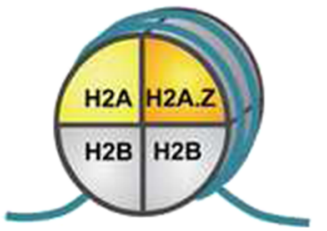

Heterotypic

\section{3) Post-translational Modifications on the different histones}

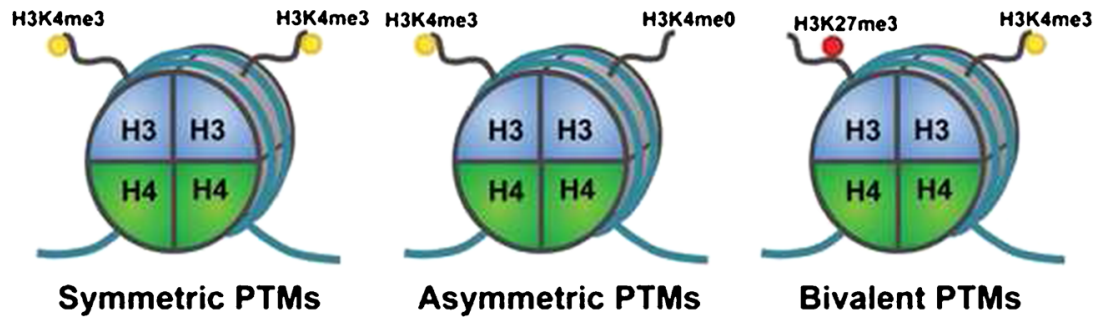


was originally thought to only be able to partner with itself within the nucleosome due to potential structural clashes between the L1 loops of H2A.Z and H2A [266]; however, it was soon discovered that H2A.Z-H2A-containing nucleosomes do exist in vitro and in vivo. The stepwise generation of these heterotypic and homotypic H2A.Z nucleosomes in yeast has been elucidated by Carl Wu's lab several years ago, and more recently, genome-wide mapping studies further showed that homotypic and heterotypic H2A.Z nucleosomes are found at different locations within the genome. In Drosophila, homotypic H2A.Z nucleosomes are enriched at regions immediately downstream of the TSS of active genes, whereas heterotypic nucleosomes are broadly distributed throughout the genome [267•]. In mouse trophoblast stem cells, homotypic H2A.Z nucleosomes are found at gene bodies, and the overall abundance of homotypic versus heterotypic H2A.Z nucleosomes changes during the cell cycle with the latter increasing from 5 to $40 \%$ abundance when cells transition from G1 to S phase [268]. While there appears to be some organism/cell type-specific differences in the distribution of homotypic versus heterotypic H2A.Z nucleosomes, there is consensus that heterotypic H2A.Z nucleosomes are thought to be less stable compared to their homotypic counterparts. Therefore, the choice of these homotypic or heterotypic H2A.Z nucleosomes offers the cell the ability to fine-tune nucleosomal stability at different genomic locations to better regulate transcription and genome stability.

In the context of PTMs, the majority of the studies to date only focus on the histone and site of modification, but almost never address whether both copies of the target histone within the nucleosome are modified the same way or not. Using epitope-tagged histones bearing mutations at some of the well-known methylation sites and purifying heterotypic nucleosomes that contain one mutant and one wild-type $\mathrm{H} 3$ or $\mathrm{H} 4$, Chen et al. showed that loss of specific methylatable lysines on one half of the nucleosome does not affect methylation of the corresponding site on the wild-type copy of $\mathrm{H} 3$ or H4 within the nucleosome [258•, 259•]. This study essentially demonstrated that asymmetrically modified nucleosomes can exist in vivo and presumably are functional in their normal cellular context. More recently, Voigt et al. combined mononucleosome purification with quantitative MS analyses and proved that both symmetrically and asymmetrically methylated H3 (H3K27me2/3) and H4 (H4K20me1) exist naturally in embryonic stem (ES), MEFs, and HeLa cells [258•, 259•]. They also found that in ES cells, the well-accepted bivalent H3K4me3/H3K27me3 mark exists within the same individual nucleosome. More interestingly, their data suggested that these methylation marks are not found on the same histone $\mathrm{H} 3$, but on the separate $\mathrm{H} 3$ copies within the same nucleosome instead. Finally, using in vitro methylation assays, the authors found that PRC2 can methylate H3K27 when the nucleosome substrate is asymmetrically methylated at $\mathrm{H} 3 \mathrm{~K} 4$ or H3K36, but not when those sites are symmetrically methylated within the nucleosome. Together, these findings indicate that the symmetric versus asymmetric status of a histone PTM can impact the downstream modification pattern of another histone site within the same nucleosome. In other words, not only can individual nucleosomes be modified symmetrically or asymmetrically, but these distinct states have real biological significances and consequences. Referring back to the theme of chemical diversity of chromatin, we now know that the mix and match of histone variants as well as the many different histone PTMs can generate innumerable combinations of physically and functionally distinct nucleosomes within the cell. With the recent recognition that histones and histone variants can be incorporated in homotypic or heterotypic fashion and that PTMs can exist in a symmetrical or asymmetrical manner (see Fig. 1), these available options can generate even more complex combinations of chromatin modifications within the nucleosome framework and extend the possible repertoire of the histone code [269].

\section{Compliance with Ethics Guidelines}

Conflict of Interest Cindy Law, Peter Cheung, and Keyur Adhvaryu declare that they have no conflict of interest.

Human and Animal Rights and Informed Consent This article does not contain any studies with human or animal subjects performed by any of the authors.

\section{References}

Papers of particular interest, published recently, have been highlighted as:

- Of importance

1. Luger K, Dechassa ML, Tremethick DJ. New insights into nucleosome and chromatin structure: an ordered state or a disordered affair? Nat Rev Mol Cell Biol. 2012;13:436-47.

2. Campos EI, Reinberg D. Histones: annotating chromatin. Annu Rev Genet. 2009;43:559-99.

3. Talbert PB, Henikoff S. Histone variants - ancient wrap artists of the epigenome. Nat Rev Mol Cell Biol. 2010;11:264-75.

4. Kouzarides T. Chromatin modifications and their function. Cell. 2007;128:693-705.

5. Voss TC, Hager GL. Dynamic regulation of transcriptional states by chromatin and transcription factors. Nat Rev Genet. 2014;15: 69-81.

6. Rando OJ, Chang HY. Genome-wide views of chromatin structure. Annu Rev Biochem. 2009;78:245-71.

7. Li G, Reinberg D. Chromatin higher-order structures and gene regulation. Curr Opin Genet Dev. 2011;21:175-86.

8. Law C, Cheung P. Histone variants and transcription regulation. Sub-cellular Biochem. 2013;61:319-41.

9. Wiedemann SM, Mildner SN, Bonisch C, Israel L, Maiser A, Matheisl S, et al. Identification and characterization of two novel primate-specific histone $\mathrm{H} 3$ variants, $\mathrm{H} 3$.X and H3.Y. J Cell Biol. 2010;190:777-91. 
10. Szenker E, Ray-Gallet D, Almouzni G. The double face of the histone variant H3.3. Cell Res. 2011;21:421-34.

11. Placek BJ, Huang J, Kent JR, Dorsey J, Rice L, Fraser NW, et al. The histone variant $\mathrm{H} 3.3$ regulates gene expression during lytic infection with herpes simplex virus type 1. J Virol. 2008;83: 1416-21.

12. Tamura T, Smith M, Kanno T, Dasenbrock H, Nishiyama A, Ozato K. Inducible deposition of the histone variant H3.3 in interferon-stimulated genes. J Biol Chem. 2009;284:12217-25.

13. Goldberg AD, Banaszynski LA, Noh K-M, Lewis PW, Elsaesser SJ, Stadler S, et al. Distinct factors control histone variant H3.3 localization at specific genomic regions. Cell. 2010;140:678-91.

14. Aida M, Hamad N, Stanlie A, Begum NA, Honjo T. Accumulation of the FACT complex, as well as histone H3.3, serves as a target marker for somatic hypermutation. Proc Natl Acad Sci U S A. 2013;110:7784-9.

15. Kraushaar DC, Jin W, Maunakea A, Abraham B, Ha M, Zhao K. Genome-wide incorporation dynamics reveal distinct categories of turnover for the histone variant H3.3. Genome Biol. 2013;14:R121.

16. Chen P, Zhao J, Wang Y, Wang M, Long H, Liang D, et al. H3.3 actively marks enhancers and primes gene transcription via opening higher-ordered chromatin. Genes Dev. 2013;27:2109-24. This paper uses in vitro biochemical assays to investigate the dynamics of histone variants exchange, in particular H2A.Z and H3.3, and their effect on chromatin structure and gene activity.

17. Nakayama T, Shimojima T, Hirose S. The PBAP remodeling complex is required for histone H3.3 replacement at chromatin boundaries and for boundary functions. Development. 2012;139: 4582-90.

18. Dunleavy EM, Almouzni G, Karpen GH. H3.3 is deposited at centromeres in $\mathrm{S}$ phase as a placeholder for newly assembled CENP-A in G(1) phase. Nucleus. 2011;2:146-57.

19. Liu CP, Xiong C, Wang M, Yu Z, Yang N, Chen P, et al. Structure of the variant histone H3.3-H4 heterodimer in complex with its chaperone DAXX. Nat Struct Mol Biol. 2012;19:1287-92.

20. Elsasser SJ, Huang H, Lewis PW, Chin JW, Allis CD, Patel DJ. DAXX envelops a histone H3.3-H4 dimer for H3.3-specific recognition. Nature. 2012;491:560-5. This paper provided the information of the crystal structure of DAXX and H3.3-H4 dimer and gave the first clue as to how this histone variant-specific chaperone is able to recognize H3.3 versus canonical H3 with only a few divergent amino acids between the two histones.

21. DeNizio JE, Elsasser SJ, Black BE. DAXX co-folds with H3.3/H4 using high local stability conferred by the $\mathrm{H} 3.3$ variant recognition residues. Nucleic Acids Res. 2014;42:4318-31.

22. Ivanauskiene K, Delbarre E, McGhie JD, Kuntziger T, Wong LH, Collas P. The PML-associated protein DEK regulates the balance of H3.3 loading on chromatin and is important for telomere integrity. Genome Res. 2014;24:1584-94.

23. Corpet A, Olbrich T, Gwerder M, Fink D, Stucki M. Dynamics of histone H3.3 deposition in proliferating and senescent cells reveals a DAXX-dependent targeting to PML-NBs important for pericentromeric heterochromatin organization. Cell Cycle. 2014;13:249-67.

24. Delbarre E, Ivanauskiene K, Kuntziger T, Collas P. DAXXdependent supply of soluble (H3.3-H4) dimers to PML bodies pending deposition into chromatin. Genome Res. 2013;23: 440-51.

25. Ng RK, Gurdon JB. Epigenetic memory of an active gene state depends on histone H3.3 incorporation into chromatin in the absence of transcription. Nat Cell Biol. 2008;10:102-9.

26. Wen D, Banaszynski LA, Liu Y, Geng F, Noh KM, Xiang J, et al. Histone variant $\mathrm{H} 3.3$ is an essential maternal factor for oocyte reprogramming. Proc Natl Acad Sci U S A. 2014;111:7325-30.
27. Jullien J, Astrand C, Szenker E, Garrett N, Almouzni G, Gurdon JB. HIRA dependent $\mathrm{H} 3.3$ deposition is required for transcriptional reprogramming following nuclear transfer to Xenopus oocytes. Epigenetics Chromatin. 2012;5:17.

28. Wen D, Banaszynski LA, Rosenwaks Z, Allis CD, Rafii S. H3.3 replacement facilitates epigenetic reprogramming of donor nuclei in somatic cell nuclear transfer embryos. Nucleus. 2014;5. The elegant experiment from this paper showed that in somatic cell nuclear transfer maternal $H 3.3$ replaces $H 3$ carrying repressive modifications in the donor nuclei to reactivate pluripotency genes.

29. Loppin B, Bonnefoy E, Anselme C, Laurencon A, Karr TL, Couble P. The histone H3.3 chaperone HIRA is essential for chromatin assembly in the male pronucleus. Nature. 2005;437: 1386-90.

30. Santenard A, Ziegler-Birling C, Koch M, Tora L, Bannister AJ, Torres-Padilla M-E. Heterochromatin formation in the mouse embryo requires critical residues of the histone variant H3.3. Nat Cell Biol. 2010;12:853-62.

31. Torres-Padilla ME, Bannister AJ, Hurd PJ, Kouzarides T, Zernicka-Goetz M. Dynamic distribution of the replacement histone variant $\mathrm{H} 3.3$ in the mouse oocyte and preimplantation embryos. Int J Dev Biol. 2006;50:455-61.

32. van der Heijden GW, Dieker JW, Derijck AA, Muller S, Berden $\mathrm{JH}$, Braat DD, et al. Asymmetry in histone $\mathrm{H} 3$ variants and lysine methylation between paternal and maternal chromatin of the early mouse zygote. Mech Dev. 2005;122:1008-22.

33. Lin CJ, Conti M, Ramalho-Santos M. Histone variant H3.3 maintains a decondensed chromatin state essential for mouse preimplantation development. Development. 2013;140:3624-34.

34. Bush KM, Yuen BT, Barrilleaux BL, Riggs JW, O'Geen H, Cotterman RF, et al. Endogenous mammalian histone H3.3 exhibits chromatin-related functions during development. Epigenetics Chromatin. 2013;6:7.

35. Yuen BT, Bush KM, Barrilleaux BL, Cotterman R, Knoepfler PS. Histone H3.3 regulates dynamic chromatin states during spermatogenesis. Development. 2014;141:3483-94.

36. Banaszynski LA, Wen D, Dewell S, Whitcomb SJ, Lin M, Diaz N, et al. Hira-dependent histone H3.3 deposition facilitates PRC2 recruitment at developmental loci in ES cells. Cell. 2013;155: 107-20.

37. Cox SG, Kim H, Garnett AT, Medeiros DM, An W, Crump JG. An essential role of variant histone $\mathrm{H} 3.3$ for ectomesenchyme potential of the cranial neural crest. PLoS Genet. 2012;8:e1002938.

38. Szenker E, Lacoste N, Almouzni G. A developmental requirement for HIRA-dependent H3.3 deposition revealed at gastrulation in Xenopus. Cell Rep. 2012;1:730-40.

39. Schwartzentruber J, Korshunov A, Liu XY, Jones DT, Pfaff E, Jacob K, et al. Driver mutations in histone H3.3 and chromatin remodelling genes in paediatric glioblastoma. Nature. 2012;482: 226-31.

40. Wu G, Broniscer A, McEachron TA, Lu C, Paugh BS, Becksfort J, et al. Somatic histone $\mathrm{H} 3$ alterations in pediatric diffuse intrinsic pontine gliomas and non-brainstem glioblastomas. Nat Genet. 2012;44:251-3.

41. Lewis PW, Muller MM, Koletsky MS, Cordero F, Lin S, Banaszynski LA, et al. Inhibition of PRC2 activity by a gain-offunction $\mathrm{H} 3$ mutation found in pediatric glioblastoma. Science. 2013;340:857-61. This paper elucidated the mechanism through which a H3.3 mutation may be contributing to gliomagenesis. They show that H3.3K27M mutant may physically associated with Ezh2 and inhibit its methyltransferase activity, thereby lowering global H3K27me3 levels.

42. Chan KM, Fang D, Gan H, Hashizume R, Yu C, Schroeder M, et al. The histone H3.3K27M mutation in pediatric glioma reprograms H3K27 methylation and gene expression. Genes Dev. 2013;27:985-90. 
43. Wratting D, Thistlethwaite A, Harris M, Zeef LA, Millar CB. A conserved function for the H2A.Z C terminus. J Biol Chem. 2012;287:19148-57.

44. Bonisch C, Schneider K, Punzeler S, Wiedemann SM, Bielmeier C, Bocola M, et al. H2A.Z.2.2 is an alternatively spliced histone H2A.Z variant that causes severe nucleosome destabilization. Nucleic Acids Res. 2012;40:5951-64. They discovered a new H2A.Z splice variant that destabilizes the nucleosome and is expressed at highest levels in brain.

45. Allis CD, Glover CVC, Bowen JK, Gorovsky MA. Histone variants specific to the transcriptionally active, amitotically dividing macronucleus of the unicellular eucaryote, Tetrahymena thermophila. Cell. 1980;20:609-17.

46. Draker R, Cheung P. Transcriptional and epigenetic functions of histone variant H2A.Z. Biochem Cell Biol. 2009;87:19-25.

47. Meneghini MD, Wu M, Madhani HD. Conserved histone variant H2A.Z protects euchromatin from the ectopic spread of silent heterochromatin. Cell. 2003;112:725-36.

48. Ogiyama Y, Ohno Y, Kubota Y, Ishii K. Epigenetically induced paucity of histone H2A.Z stabilizes fission-yeast ectopic centromeres. Nat Struct Mol Biol. 2013;20:1397-406.

49. Hou H, Wang Y, Kallgren SP, Thompson J, Yates JR, Jia S. Histone variant H2A.Z regulates centromere silencing and chromosome segregation in fission yeast. J Biol Chem. 2009;285: 1909-18.

50. Sharma U, Stefanova D, Holmes SG. Histone variant H2A.Z functions in sister chromatid cohesion in Saccharomyces cerevisiae. Mol Cell Biol. 2013;33:3473-81.

51. Xu Y, Ayrapetov MK, Xu C, Gursoy-Yuzugullu O, Hu Y, Price BD. Histone H2A.Z controls a critical chromatin remodeling step required for DNA double-strand break repair. Mol Cell. 2012;48: 723-33.

52. Yu Y, Deng Y, Reed SH, Millar CB, Waters R. Histone variant Htz1 promotes histone $\mathrm{H} 3$ acetylation to enhance nucleotide excision repair in Htz1 nucleosomes. Nucleic Acids Res. 2013;41: 9006-19.

53. Mao Z, Pan L, Wang W, Sun J, Shan S, Dong Q, et al. Anp32e, a higher eukaryotic histone chaperone directs preferential recognition for H2A.Z. Cell Res. 2014;24:389-99.

54. Obri A, Ouararhni K, Papin C, Diebold ML, Padmanabhan K, Marek M, et al. ANP32E is a histone chaperone that removes H2A.Z from chromatin. Nature. 2014;505:648-53. This paper identified and characterized a new H2A.Z-specific chaperone, Anp32e, that may have specific functions in the removal of H2A.Z from enhancers.

55. Altaf M, Auger A, Monnet-Saksouk J, Brodeur J, Piquet S, Cramet $\mathrm{M}$, et al. NuA4-dependent acetylation of nucleosomal histones $\mathrm{H} 4$ and $\mathrm{H} 2 \mathrm{~A}$ directly stimulates incorporation of H2A.Z by the SWR1 complex. J Biol Chem. 2010;285:15966-77.

56. Ranjan A, Mizuguchi G, FitzGerald PC, Wei D, Wang F, Huang Y, et al. Nucleosome-free region dominates histone acetylation in targeting SWR1 to promoters for H2A.Z replacement. Cell. 2013;154:1232-45.

57. Watanabe S, Radman-Livaja M, Rando OJ, Peterson CL. A histone acetylation switch regulates H2A.Z deposition by the SWR-C remodeling enzyme. Science. 2013;340:195-9.

58. Papamichos-Chronakis M, Watanabe S, Rando OJ, Peterson CL. Global regulation of H2A.Z localization by the INO 80 chromatinremodeling enzyme is essential for genome integrity. Cell. 2011;144:200-13.

59. Zlatanova J, Thakar A. H2A.Z: view from the top. Structure. 2008;16:166-79.

60. Bellucci L, Dalvai M, Kocanova S, Moutahir F, Bystricky K. Activation of $\mathrm{p} 21$ by HDAC inhibitors requires acetylation of H2A.Z. PLoS One. 2013;8:e54102.
61. Zerzaihi O, Chriett S, Vidal H, Pirola L. Insulin-dependent transcriptional control in L6 rat myotubes is associated with modulation of histone acetylation and accumulation of the histone variant H2A.Z in the proximity of the transcriptional start site. Biochem Cell Biol. 2014;92:61-7.

62. Draker R, Ng MK, Sarcinella E, Ignatchenko V, Kislinger T, Cheung P. A combination of H2A.Z and H4 acetylation recruits $\mathrm{Brd} 2$ to chromatin during transcriptional activation. PLoS Genet. 2012;8:e1003047.

63. Yang X, Noushmehr H, Han H, Andreu-Vieyra C, Liang G, Jones PA. Gene reactivation by 5-aza-2'-deoxycytidine-induced demethylation requires SRCAP-mediated H2A.Z insertion to establish nucleosome depleted regions. PLoS Genet. 2012;8:e1002604.

64. Creyghton MP, Markoulaki S, Levine SS, Hanna J, Lodato MA, Sha K, et al. H2AZ is enriched at polycomb complex target genes in ES cells and is necessary for lineage commitment. Cell. 2008;135:649-61.

65. Hu G, Cui K, Northrup D, Liu C, Wang C, Tang Q, et al. H2A.Z facilitates access of active and repressive complexes to chromatin in embryonic stem cell self-renewal and differentiation. Cell Stem Cell. 2013;12:180-92. This paper has elucidated the role of $H 2 A . Z$ at enhancers and promoters in ES cells and that it is required for both self-renewal and differentiation of murine ES cells. H2A.Z was associated with chromatin accessibility at gene regulatory regions and played a prominent role in the regulation of pluripotency and differentiation genes.

66. Couture JP, Nolet G, Beaulieu E, Blouin R, Gevry N. The $\mathrm{p} 400 / \mathrm{Brd} 8$ chromatin remodeling complex promotes adipogenesis by incorporating histone variant H2A.Z at PPARgamma target genes. Endocrinology. 2012;153:5796-808.

67. Shibata Y, Sawa H, Nishiwaki K. HTZ-1/H2A.z and MYS-1/ MYST HAT act redundantly to maintain cell fates in somatic gonadal cells through repression of ceh-22 in C. elegans. Development. 2014;141:209-18.

68. Ku M, Jaffe JD, Koche RP, Rheinbay E, Endoh M, Koseki H, et al. H2A.Z landscapes and dual modifications in pluripotent and multipotent stem cells underlie complex genome regulatory functions. Genome Biol. 2012;13:R85. Genome-wide mapping of $H 2 A . Z$ in this paper shows that this variant is present at promoters, enhancers and poised promoters with bivalent chromatin in ES cells. They also found that H2A.Z found at bivalent chromatin is dually-modified by ubiquitylation and acetylation.

69. Li Z, Gadue P, Chen K, Jiao Y, Tuteja G, Schug J, et al. Foxa2 and H2A.Z mediate nucleosome depletion during embryonic stem cell differentiation. Cell. 2012;151:1608-16.

70. Thakar A, Gupta P, Ishibashi T, Finn R, Silva-Moreno B, Uchiyama S, et al. H2A.Z and H3.3 histone variants affect nucleosome structure: biochemical and biophysical studies. Biochemistry. 2009;48:10852-7.

71. Jin C, Zang C, Wei G, Cui K, Peng W, Zhao K, et al. H3.3/H2A.Z double variant-containing nucleosomes mark 'nucleosome-free regions' of active promoters and other regulatory regions. Nat Genet. 2009;41:941-5.

72. Kim K, Punj V, Choi J, Heo K, Kim JM, Laird PW, et al. Gene dysregulation by histone variant H2A.Z in bladder cancer. Epigenetics Chromatin. 2013;6:34.

73. Lee K, Lau ZZ, Meredith C, Park JH. Decrease of p400 ATPase complex and loss of H2A.Z within the p21 promoter occur in senescent IMR-90 human fibroblasts. Mech Ageing Dev. 2012;133:686-94.

74. Gatta R, Mantovani R. NF-Y affects histone acetylation and H2A.Z deposition in cell cycle promoters. Epigenetics: Off $\mathbf{J}$ DNA Methylation Soc. 2011;6.

75. Dryhurst D, McMullen B, Fazli L, Rennie PS, Ausio J. Histone H2A.Z prepares the prostate specific antigen (PSA) gene for androgen receptor-mediated transcription and is upregulated in a 
model of prostate cancer progression. Cancer Lett. 2012;315: $38-47$.

76. Talbert PB, Ahmad K, Almouzni G, Ausio J, Berger F, Bhalla PL, et al. A unified phylogeny-based nomenclature for histone variants. Epigenetics Chromatin. 2012;5:7.

77. Chadwick BP, Willard HF. A novel chromatin protein, distantly related to histone $\mathrm{H} 2 \mathrm{~A}$, is largely excluded from the inactive $\mathrm{X}$ chromosome. J Cell Biol. 2001;152:375.

78. González-Romero R, Méndez J, Ausió J, Eirín-López JM. Quickly evolving histones, nucleosome stability and chromatin folding: all about histone H2A.Bbd. Gene. 2008;413:1-7.

79. Doyen CM, Montel F, Gautier T, Menoni H, Claudet C, DelacourLarose $\mathrm{M}$, et al. Dissection of the unusual structural and functional properties of the variant H2A.Bbd nucleosome. EMBO J. 2006;25:4234-44.

80. Arimura Y, Kimura H, Oda T, Sato K, Osakabe A, Tachiwana H, et al. Structural basis of a nucleosome containing histone H2A.B/ H2A.Bbd that transiently associates with reorganized chromatin. Sci Rep. 2013;3:3510. Biochemical analysis in this paper showed that H2A.B can form hexasomes and octasomes with shorter segments of DNA. They proposed an interesting hypothesis that H2A.B may rapidly form nucleosomes with short segments of DNA during DNA-templated processes to transiently stabilize DNA.

81. Sugiyama M, Arimura Y, Shirayama K, Fujita R, Oba Y, Sato N, et al. Distinct features of the histone core structure in nucleosomes containing the histone H2A.B variant. Biophys J. 2014;106:220613.

82. Sansoni V, Casas-Delucchi CS, Rajan M, Schmidt A, Bonisch C, Thomae AW, et al. The histone variant H2A.Bbd is enriched at sites of DNA synthesis. Nucleic Acids Res. 2014;42:6405-20.

83. Tolstorukov MY, Goldman JA, Gilbert C, Ogryzko V, Kingston RE, Park PJ. Histone variant H2A.Bbd is associated with active transcription and mRNA processing in human cells. Mol Cell. 2012;47:596-607.

84. Nekrasov M, Soboleva TA, Jack C, Tremethick DJ. Histone variant selectivity at the transcription start site: H2A.Z or H2A.Lap1. Nucleus. 2013;4:431-8.

85. Gamble MJ, Kraus WL. Multiple facets of the unique histone variant macroH2A: from genomics to cell biology. Cell Cycle. 2010;9:2568-74.

86. Ioudinkova ES, Barat A, Pichugin A, Markova E, Sklyar I, Pirozhkova I, et al. Distinct distribution of ectopically expressed histone variants $\mathrm{H} 2 \mathrm{~A}$.Bbd and $\mathrm{MacroH} 2 \mathrm{~A}$ in open and closed chromatin domains. PLoS One. 2012;7:e47157.

87. Chakravarthy S, Patel A, Bowman GD. The basic linker of macroH2A stabilizes DNA at the entry/exit site of the nucleosome. Nucleic Acids Res. 2012;40:8285-95.

88. Kim JM, Heo K, Choi J, Kim K, An W. The histone variant MacroH2A regulates $\mathrm{Ca}(2+)$ influx through TRPC3 and TRPC6 channels. Oncogenesis. 2013;2:e77.

89. Pehrson JR, Changolkar LN, Costanzi C, Leu NA. Mice without MacroH2A histone variants. Mol Cell Biol. 2014. This group has generated a macroH2A1 and macroH2A2 double knock mouse for the first time. They found that these mice had impaired growth and reduced reproductive efficiency as well as aberrant gene expression in the liver.

90. Buschbeck M, Uribesalgo I, Wibowo I, Rué P, Martin D, Gutierrez A, et al. The histone variant macroH2A is an epigenetic regulator of key developmental genes. Nat Struct Mol Biol. 2009;16:1074-9.

91. Pasque V, Gillich A, Garrett N, Gurdon JB. Histone variant macroH2A confers resistance to nuclear reprogramming. EMBO J. 2011;30:2373-87.

92. Pasque V, Halley-Stott RP, Gillich A, Garrett N, Gurdon JB. Epigenetic stability of repressed states involving the histone variant macroH2A revealed by nuclear transfer to Xenopus oocytes. Nucleus. 2011;2:533-9.

93. Pasque V, Radzisheuskaya A, Gillich A, Halley-Stott RP, Panamarova M, Zernicka-Goetz M, et al. Histone variant macroH2A marks embryonic differentiation in vivo and acts as an epigenetic barrier to induced pluripotency. J Cell Sci. 2012;125:6094-104. This paper showed that macroH2A is a barrier to reprogramming and that knockdown of macroH2A allows for more efficient reprogramming in induced pluripotency cells. Overexpression of macroH $2 \mathrm{~A}$ prevented efficient reprogramming.

94. Gaspar-Maia A, Qadeer ZA, Hasson D, Ratnakumar K, Leu NA, Leroy $\mathrm{G}$, et al. MacroH2A histone variants act as a barrier upon reprogramming towards pluripotency. Nat Commun. 2013;4: 1565.

95. Lei S, Long J, Li J. MacroH2A suppresses the proliferation of the B16 melanoma cell line. Mol Med Rep. 2014;10:1845-50.

96. Yuan J, Adamski R, Chen J. Focus on histone variant H2AX: to be or not to be. FEBS Lett. 2010;584:3717-24.

97. Rogakou EP, Pilch DR, Orr AH, Ivanova VS, Bonner WM. DNA double-stranded breaks induce histone H2AX phosphorylation on serine 139. J Biol Chem. 1998;273:5858-68.

98. Rogakou EP, Sekeri-Pataryas KE. Histone variants of H2A and $\mathrm{H} 3$ families are regulated during in vitro aging in the same manner as during differentiation. Exp Gerontol. 1999;34:741-54.

99. Redon CE, Weyemi U, Parekh PR, Huang D, Burrell AS, Bonner WM. gamma-H2AX and other histone post-translational modifications in the clinic. Biochim Biophys Acta. 2012;1819:743-56.

100. Paull TT, Rogakou EP, Yamazaki V, Kirchgessner CU, Gellert M, Bonner WM. A critical role for histone H2AX in recruitment of repair factors to nuclear foci after DNA damage. Curr Biol: CB. 2000;10:886-95

101. Xiao A, Li H, Shechter D, Ahn SH, Fabrizio LA, ErdjumentBromage $\mathrm{H}$, et al. WSTF regulates the H2A.X DNA damage response via a novel tyrosine kinase activity. Nature. 2009;457: 57-62.

102. Cook PJ, Ju BG, Telese F, Wang X, Glass CK, Rosenfeld MG. Tyrosine dephosphorylation of H2AX modulates apoptosis and survival decisions. Nature. 2009;458:591-6.

103. Singh N, Basnet H, Wiltshire TD, Mohammad DH, Thompson JR, Heroux A, et al. Dual recognition of phosphoserine and phosphotyrosine in histone variant H2A.X by DNA damage response protein MCPH1. Proc Natl Acad Sci U S A. 2012;109: 14381-6.

104. Zhu F, Zykova TA, Peng C, Zhang J, Cho YY, Zheng D, et al Phosphorylation of H2AX at Ser139 and a new phosphorylation site Ser16 by RSK2 decreases H2AX ubiquitination and inhibits cell transformation. Cancer Res. 2011;71:393-403.

105. Solier S, Pommier Y. The nuclear gamma-H2AX apoptotic ring: implications for cancers and autoimmune diseases. Cell Mol Life Sci: CMLS. 2014;71:2289-97.

106. Solier S, Pommier Y. The apoptotic ring: a novel entity with phosphorylated histones $\mathrm{H} 2 \mathrm{AX}$ and $\mathrm{H} 2 \mathrm{~B}$ and activated DNA damage response kinases. Cell Cycle. 2009;8:1853-9.

107. Strahl BD, Allis CD. The language of covalent histone modifications. Nature. 2000;403:41-5.

108. Jenuwein T, Allis CD. Translating the histone code. Science. 2001;293:1074-80.

109. Henikoff S, Shilatifard A. Histone modification: cause or cog? Trends Genet. 2011;27:389-96.

110. Ptashne M. Epigenetics: core misconcept. Proc Natl Acad Sci U S A. 2013;110:7101-3.

111. Ptashne M. On the use of the word 'epigenetic'. Curr Biol. 2007;17:R233-6.

112. Taverna SD, Ilin S, Rogers RS, Tanny JC, Lavender H, Li H, et al. Yng1 PHD finger binding to $\mathrm{H} 3$ trimethylated at $\mathrm{K} 4$ promotes 
NuA3 HAT activity at K14 of $\mathrm{H} 3$ and transcription at a subset of targeted ORFs. Mol Cell. 2006;24:785-96.

113. Baker LA, Allis CD, Wang GG. PHD fingers in human diseases: disorders arising from misinterpreting epigenetic marks. Mut Res/ Fundam Mol Mech Mutagen. 2008;647:3-12.

114. Ruthenburg AJ, Li H, Patel DJ, Allis CD. Multivalent engagement of chromatin modifications by linked binding modules. Nat Rev Mol Cell Biol. 2007;8:983-94.

115. Musselman CA, Lalonde M-E, Cote J, Kutateladze TG. Perceiving the epigenetic landscape through histone readers. Nat Struct Mol Biol. 2012;19:1218-27.

116. Patel DJ, Wang Z. Readout of epigenetic modifications. Annu Rev Biochem. 2013;82:81-118.

117. Eskandarian HA, Impens F, Nahori MA, Soubigou G, Coppee JY, Cossart P, et al. A role for SIRT2-dependent histone H3K18 deacetylation in bacterial infection. Science. 2013;341:1238858. This paper demonstrates hijacking of the histone deacetylation machinery by bacterial pathogens, a novel aspect of chromatin modifications.

118. Kadyrova LY, Mertz TM, Zhang Y, Northam MR, Sheng Z, Lobachev KS, et al. A reversible histone $\mathrm{H} 3$ acetylation cooperates with mismatch repair and replicative polymerases in maintaining genome stability. PLoS Genet. 2013;9: e1003899.

119. Munoz-Galvan S, Jimeno S, Rothstein R, Aguilera A. Histone H3K56 acetylation, Rad52, and non-DNA repair factors control double-strand break repair choice with the sister chromatid. PLoS Genet. 2013;9:e1003237.

120. Clemente-Ruiz M, Gonzalez-Prieto R, Prado F. Histone H3K56 acetylation, CAF1, and Rtt106 coordinate nucleosome assembly and stability of advancing replication forks. PLoS Genet. 2011;7: e1002376.

121. Di Cerbo V, Mohn F, Ryan DP, Montellier E, Kacem S, Tropberger $\mathrm{P}$, et al. Acetylation of histone $\mathrm{H} 3$ at lysine 64 regulates nucleosome dynamics and facilitates transcription. Elife. 2014;3:e1632.

122. Tropberger P, Pott S, Keller C, Kamieniarz-Gdula K, Caron M, Richter F, et al. Regulation of transcription through acetylation of H3K122 on the lateral surface of the histone octamer. Cell. 2013;152:859-72. This paper uncovers the regulation of transcription by a novel site of acetylation, H3K122, on the lateral surface of the histone octamer.

123. Wang F, Dai J, Daum JR, Niedzialkowska E, Banerjee B, Stukenberg PT, et al. Histone H3 Thr-3 phosphorylation by Haspin positions Aurora B at centromeres in mitosis. Science. 2010;330:231-5.

124. Varier RA, Outchkourov NS, de Graaf P, van Schaik FMA, Ensing HJL, Wang F, et al. A phospho/methyl switch at histone $\mathrm{H} 3$ regulates TFIID association with mitotic chromosomes. EMBO J. 2010;29:3967-78.

125. Liokatis S, Stutzer A, Elsasser SJ, Theillet FX, Klingberg R, van Rossum B, et al. Phosphorylation of histone H3 Ser10 establishes a hierarchy for subsequent intramolecular modification events. Nat Struct Mol Biol. 2012;19:819-23. This study makes an important contribution to our understanding of cross-talk between H3S10ph, H3T6ph, H3T11ph and H3K14ac.

126. Metzger E, Imhof A, Patel D, Kahl P, Hoffmeyer K, Friedrichs N, et al. Phosphorylation of histone H3T6 by PKCbeta(I) controls demethylation at histone H3K4. Nature. 2010;464:792-6.

127. Hammond SL, Byrum SD, Namjoshi S, Graves HK, Dennehey BK, Tackett AJ, et al. Mitotic phosphorylation of histone $\mathrm{H} 3$ threonine 80. Cell Cycle. 2014;13:440-52.

128. Lau AT, Lee SY, Xu YM, Zheng D, Cho YY, Zhu F, et al. Phosphorylation of histone $\mathrm{H} 2 \mathrm{~B}$ serine 32 is linked to cell transformation. J Biol Chem. 2011;286:26628-37.
129. Bungard D, Fuerth BJ, Zeng P-Y, Faubert B, Maas NL, Viollet B, et al. Signaling kinase AMPK activates stress-promoted transcription via histone H2B phosphorylation. Science. 2010;329:1201-5.

130. Yu Y, Song C, Zhang Q, DiMaggio PA, Garcia BA, York A, et al. Histone $\mathrm{H} 3$ lysine 56 methylation regulates DNA replication through its interaction with PCNA. Mol Cell. 2012;46:7-17.

131. Daujat S, Weiss T, Mohn F, Lange UC, Ziegler-Birling C, Zeissler $\mathrm{U}$, et al. H3K64 trimethylation marks heterochromatin and is dynamically remodeled during developmental reprogramming. Nat Struct Mol Biol. 2009;16:777-81.

132. Mattiroli F, Vissers JH, van Dijk WJ, Ikpa P, Citterio E, Vermeulen W, et al. RNF168 ubiquitinates K13-15 on H2A/H2AX to drive DNA damage signaling. Cell. 2012;150:1182-95. This paper reports H2AK13-15 ubiquitination as a novel mark that is established by $R N F 168$ and read by $p 53$ in DNA repair pathways.

133. Wu L, Zee BM, Wang Y, Garcia BA, Dou Y. The RING finger protein MSL2 in the MOF complex is an E3 ubiquitin ligase for H2B K34 and is involved in crosstalk with $\mathrm{H} 3 \mathrm{~K} 4$ and $\mathrm{K} 79$ methylation. Mol Cell. 2011;43:132-44

134. Wu L, Li L, Zhou B, Qin Z, Dou Y. H2B ubiquitylation promotes RNA Pol II processivity via PAF1 and pTEFb. Mol Cell. 2014;54: 920-31.

135. Nishiyama A, Yamaguchi L, Sharif J, Johmura Y, Kawamura T, Nakanishi K, et al. Uhrf1-dependent H3K23 ubiquitylation couples maintenance DNA methylation and replication. Nature. 2013;502:249-53. This paper reports and characterizes $H 3 K 23 u b$, a novel site of ubiquitination.

136. Kim K, Lee B, Kim J, Choi J, Kim J-M, Xiong Y, et al. Linker histone H1.2 cooperates with Cul4A and PAF1 to drive H4K31 ubiquitylation-mediated transactivation. Cell Rep. 2013;5: 1690-703.

137. Rivera CM, Ren B. Mapping human epigenomes. Cell. 2013;155: $39-55$.

138. Rothbart SB, Strahl BD. Interpreting the language of histone and DNA modifications. BBA - Gene Regul Mech. 2014;1839: 627-43.

139. Du J, Patel DJ. Structural biology-based insights into combinatorial readout and crosstalk among epigenetic marks. BBA - Gene Regul Mech. 2014;1839:719-27.

140. Allfrey VG, Mirsky AE. Structural modifications of histones and their possible role in the regulation of RNA synthesis. Science. 1964;144:559.

141. Allfrey VG, Faulkner R, Mirsky AE. Acetylation and methylation of histones and their possible role in the regulation of RNA synthesis. Proc Natl Acad Sci U S A. 1964;51:786-94.

142. Brownell JE, Zhou J, Ranalli T, Kobayashi R, Edmondson DG, Roth SY, et al. Tetrahymena histone acetyltransferase A: a homo$\log$ to yeast $\mathrm{Gcn} 5 \mathrm{p}$ linking histone acetylation to gene activation. Cell. 1996;84:843-51.

143. Mizzen CA, Yang XJ, Kokubo T, Brownell JE, Bannister AJ, Owen-Hughes T, et al. The TAF(II)250 subunit of TFIID has histone acetyltransferase activity. Cell. 1996;87:1261-70.

144. Kuo MH, Brownell JE, Sobel RE, Ranalli TA, Cook RG, Edmondson DG, et al. Transcription-linked acetylation by Gen $5 p$ of histones H3 and H4 at specific lysines. Nature. 1996;383:269-72.

145. Bode J. Nucleosomal conformations induced by the small HMG proteins or by histone hyperacetylation are distinct. Arch Biochem Biophys. 1984;228:364-72.

146. Libertini LJ, Ausio J, van Holde KE, Small EW. Histone hyperacetylation. Its effects on nucleosome core particle transitions. Biophys J. 1988;53:477-87.

147. Wang X, Hayes JJ. Acetylation mimics within individual core histone tail domains indicate distinct roles in regulating the stability of higher-order chromatin structure. Mol Cell Biol. 2008;28:227-36. 
148. Sanchez R, Meslamani J, Zhou M-M. The bromodomain: from epigenome reader to druggable target. Biochim Biophys Acta. 2014;1839:676-85.

149. Tropberger P, Schneider R. Scratching the (lateral) surface of chromatin regulation by histone modifications. Nat Struct Mol Biol. 2013;20:657-61.

150. Xu F, Zhang K, Grunstein M. Acetylation in histone $\mathrm{H} 3$ globular domain regulates gene expression in yeast. Cell. 2005;121: 375-85.

151. Masumoto H, Hawke D, Kobayashi R, Verreault A. A role for cell-cycle-regulated histone $\mathrm{H} 3$ lysine 56 acetylation in the DNA damage response. Nature. 2005;436:294-8.

152. Recht J, Tsubota T, Tanny JC, Diaz RL, Berger JM, Zhang X, et al. Histone chaperone Asfl is required for histone $\mathrm{H} 3$ lysine 56 acetylation, a modification associated with $\mathrm{S}$ phase in mitosis and meiosis. Proc Natl Acad Sci U S A. 2006;103:6988-93.

153. Li Q, Zhou H, Wurtele H, Davies B, Horazdovsky B, Verreault A, et al. Acetylation of histone $\mathrm{H} 3$ lysine 56 regulates replicationcoupled nucleosome assembly. Cell. 2008;134:244-55.

154. Tanaka A, Tanizawa H, Sriswasdi S, Iwasaki O, Chatterjee AG, Speicher DW, et al. Epigenetic regulation of condensin-mediated genome organization during the cell cycle and upon DNA damage through histone H3 lysine 56 acetylation. Mol Cell. 2012;48: 532-46.

155. Harris RA, Bowker-Kinley MM, Huang B, Wu P. Regulation of the activity of the pyruvate dehydrogenase complex. Adv Enzym Regul. 2002;42:249-59.

156. Stacpoole PW. The pyruvate dehydrogenase complex as a therapeutic target for age-related diseases. Aging Cell. 2012;11:371-7.

157. Takahashi H, McCaffery JM, Irizarry RA, Boeke JD. Nucleocytosolic acetyl-coenzyme a synthetase is required for histone acetylation and global transcription. Mol Cell. 2006;23:207-17.

158. Wellen KE, Hatzivassiliou G, Sachdeva UM, Bui TV, Cross JR, Thompson CB. ATP-citrate lyase links cellular metabolism to histone acetylation. Science. 2009;324:1076-80.

159. Sutendra G, Kinnaird A, Dromparis P, Paulin R, Stenson TH, Haromy A, et al. A nuclear pyruvate dehydrogenase complex is important for the generation of acetyl-CoA and histone acetylation. Cell. 2014;158:84-97. This study uncovers a novel nuclear source of acetyl-CoA for histone acetylation.

160. Vander Heiden MG, Cantley LC, Thompson CB. Understanding the Warburg effect: the metabolic requirements of cell proliferation. Science (New York, NY). 2009;324:1029-33.

161. Kaelin WG, McKnight SL. Influence of metabolism on epigenetics and disease. Cell. 2013;153:56-69.

162. Xu D, Bai J, Duan Q, Costa M, Dai W. Covalent modifications of histones during mitosis and meiosis. Cell Cycle. 2009;8:3688-94.

163. Pérez-Cadahía B, Drobic B, Davie JR. H3 phosphorylation: dual role in mitosis and interphase. Biochem Cell Biol $=$ Biochimie et biologie cellulaire. 2009;87:695-709.

164. Healy S, Khan P, He S, Davie JR. Histone H3 phosphorylation, immediate-early gene expression, and the nucleosomal response: a historical perspective. Biochem Cell Biol = Biochimie et biologie cellulaire. 2012;90:39-54.

165. Cheung P, Allis CD, Sassone-Corsi P. Signaling to chromatin through histone modifications. Cell. 2000;103:263-71.

166. Talasz H, Helliger W, Sarg B, Debbage PL, Puschendorf B, Lindner H. Hyperphosphorylation of histone H2A.X and dephosphorylation of histone $\mathrm{H} 1$ subtypes in the course of apoptosis. Cell Death Differ. 2002;9:27-39.

167. Dickey JS, Redon CE, Nakamura AJ, Baird BJ, Sedelnikova OA, Bonner WM. H2AX: functional roles and potential applications. Chromosoma. 2009;118:683-92.
168. Ajiro K. Histone H2B phosphorylation in mammalian apoptotic cells. An association with DNA fragmentation. J Biol Chem. 2000;275:439-43.

169. Cheung WL, Ajiro K, Samejima K, Kloc M, Cheung P, Mizzen CA, et al. Apoptotic phosphorylation of histone $\mathrm{H} 2 \mathrm{~B}$ is mediated by mammalian sterile twenty kinase. Cell. 2003; 113:507-17.

170. Ahn S-H, Cheung WL, Hsu J-Y, Diaz RL, Smith MM, Allis CD. Sterile 20 kinase phosphorylates histone $\mathrm{H} 2 \mathrm{~B}$ at serine 10 during hydrogen peroxide-induced apoptosis in S. cerevisiae. Cell. 2005;120:25-36.

171. Füllgrabe J, Hajji N, Joseph B. Cracking the death code: apoptosis-related histone modifications. Cell Death Differ. 2010;17:1238-43.

172. Roth SY, Allis CD. Chromatin condensation: does histone H1 dephosphorylation play a role? Trends Biochem Sci. 1992;17: 93-8.

173. Sawicka A, Seiser C. Sensing core histone phosphorylation-a matter of perfect timing. BBA - Gene Regul Mech. 2014;1839: $711-8$.

174. Rossetto D, Avvakumov N, Cote J. Histone phosphorylation: a chromatin modification involved in diverse nuclear events. Epigenetics: Off J DNA Methylation Soc. 2012;7:1098-108.

175. Wilkins BJ, Rall NA, Ostwal Y, Kruitwagen T, Hiragami-Hamada $\mathrm{K}$, Winkler $\mathrm{M}$, et al. A cascade of histone modifications induces chromatin condensation in mitosis. Science. 2014;343:77-80. This paper dissects the relationship between H3S10 phosphorylation and chromosome condensation.

176. Robinson PJ, An W, Routh A, Martino F, Chapman L, Roeder RG, et al. $30 \mathrm{~nm}$ chromatin fibre decompaction requires both H4-K16 acetylation and linker histone eviction. J Mol Biol. 2008;381: 816-25.

177. Shogren-Knaak M, Ishii H, Sun JM, Pazin MJ, Davie JR, Peterson CL. Histone H4-K16 acetylation controls chromatin structure and protein interactions. Science. 2006;311:844-7.

178. Shogren-Knaak M, Peterson CL. Switching on chromatin: mechanistic role of histone H4-K16 acetylation. Cell Cycle. 2006;5: 1361-5.

179. Chahal SS, Matthews HR, Bradbury EM. Acetylation of histone $\mathrm{H} 4$ and its role in chromatin structure and function. Nature. 1980;287:76-9.

180. Yamagishi Y, Honda T, Tanno Y, Watanabe Y. Two histone marks establish the inner centromere and chromosome bi-orientation. Science. 2010;330:239-43.

181. Suganuma T, Workman JL. MAP kinases and histone modification. J Mol Cell Biol. 2012;4:348-50.

182. Suganuma T, Workman JL. Chromatin and signaling. Curr Opin Cell Biol. 2013;25:322-6.

183. Cheung P, Tanner KG, Cheung WL, Sassone-Corsi P, Denu JM, Allis CD. Synergistic coupling of histone $\mathrm{H} 3$ phosphorylation and acetylation in response to epidermal growth factor stimulation. Mol Cell. 2000;5:905-15.

184. Clayton AL, Rose S, Barratt MJ, Mahadevan LC. Phosphoacetylation of histone $\mathrm{H} 3$ on c-fos- and c-jun-associated nucleosomes upon gene activation. EMBO J. 2000;19:3714-26.

185. Zippo A, Serafini R, Rocchigiani M, Pennacchini S, Krepelova A, Oliviero S. Histone crosstalk between H3S10ph and H4K16ac generates a histone code that mediates transcription elongation. Cell. 2009;138:1122-36.

186. Lau PN, Cheung P. Elucidating combinatorial histone modifications and crosstalks by coupling histone-modifying enzyme with biotin ligase activity. Nucleic Acids Res. 2013;41:e49.

187. Dawson MA, Foster SD, Bannister AJ, Robson SC, Hannah R, Wang X, et al. Three distinct patterns of histone H3Y41 phosphorylation mark active genes. Cell Rep. 2012;2:470-7. 
188. Dawson MA, Bannister AJ, Gottgens B, Foster SD, Bartke T, Green AR, et al. JAK2 phosphorylates histone H3Y41 and excludes HP1alpha from chromatin. Nature. 2009;461:819-22.

189. Basnet H, Su XB, Tan Y, Meisenhelder J, Merkurjev D, Ohgi KA, et al. Tyrosine phosphorylation of histone $\mathrm{H} 2 \mathrm{~A}$ by $\mathrm{CK} 2$ regulates transcriptional elongation. Nature. 2014;516:267-71.

190. Papamichos-Chronakis M, Peterson CL. Chromatin and the genome integrity network. Nat Rev Genet. 2013;14:62-75.

191. Lee C-S, Lee K, Legube G, Haber JE. Dynamics of yeast histone $\mathrm{H} 2 \mathrm{~A}$ and $\mathrm{H} 2 \mathrm{~B}$ phosphorylation in response to a double-strand break. Nat Struct Mol Biol. 2014;21:103-9. This paper presents a novel histone phosphorylation site, H2B129ph and its relationship to yeast $H 2 A$ phosphorylation (equivalent to $\gamma H 2 A X$ ) in DNA repair.

192. Baker SP, Phillips J, Anderson S, Qiu Q, Shabanowitz J, Smith MM, et al. Histone H3 Thr 45 phosphorylation is a replicationassociated post-translational modification in S. cerevisiae. Nat Cell Biol. 2010;12:294-8

193. Hurd PJ, Bannister AJ, Halls K, Dawson MA, Vermeulen M, Olsen JV, et al. Phosphorylation of histone H3 Thr-45 is linked to apoptosis. J Biol Chem. 2009;284:16575-83.

194. Ismail HM, Hurd PJ, Khalil MI, Kouzarides T, Bannister A, Gout I. S6 kinase 2 is bound to chromatin-nuclear matrix cellular fractions and is able to phosphorylate histone $\mathrm{H} 3$ at threonine 45 in vitro and in vivo. J Cell Biochem. 2014;115:1048-62.

195. Mahajan K, Fang B, Koomen JM, Mahajan NP. H2B Tyr37 phosphorylation suppresses expression of replication-dependent core histone genes. Nat Struct Mol Biol. 2012;19:930-7.

196. Singh RK, Kabbaj MH, Paik J, Gunjan A. Histone levels are regulated by phosphorylation and ubiquitylation-dependent proteolysis. Nat Cell Biol. 2009;11:925-33.

197. Hsu JY, Sun ZW, Li X, Reuben M, Tatchell K, Bishop DK, et al. Mitotic phosphorylation of histone $\mathrm{H} 3$ is governed by Ipl1/aurora kinase and Glc7/PP1 phosphatase in budding yeast and nematodes. Cell. 2000;102:279-91.

198. Nowak SJ, Pai C-Y, Corces VG. Protein phosphatase 2A activity affects histone $\mathrm{H} 3$ phosphorylation and transcription in Drosophila melanogaster. Mol Cell Biol. 2003;23:6129-38.

199. Zhang H, Wang Z, Zhang Z. PP1 $\alpha$, PP1 $\beta$ and Wip-1 regulate H4S47 phosphorylation and deposition of histone $\mathrm{H} 3$ variant H3.3. Nucleic Acids Res. 2013;41:8085-93.

200. Qian J, Lesage B, Beullens M, van Eynde A, Bollen M. PP1/ Repo-man dephosphorylates mitotic histone $\mathrm{H} 3$ at $\mathrm{T} 3$ and regulates chromosomal aurora B targeting. Curr Biol. 2011;21:766-73.

201. Shimada M, Haruta M, Niida H, Sawamoto K, Nakanishi M. Protein phosphatase $1 \gamma$ is responsible for dephosphorylation of histone H3 at Thr 11 after DNA damage. EMBO Rep. 2010;11: 883-9.

202. Macůrek L, Lindqvist A, Voets O, Kool J, Vos HR, Medema RH. Wip1 phosphatase is associated with chromatin and dephosphorylates gammaH2 $\mathrm{AX}$ to promote checkpoint inhibition. Oncogene. 2010;29:2281-91.

203. Bazzi M, Mantiero D, Trovesi C, Lucchini G, Longhese MP. Dephosphorylation of gamma H2A by Glc7/protein phosphatase 1 promotes recovery from inhibition of DNA replication. Mol Cell Biol. 2010;30:131-45.

204. Adhvaryu KK, Selker EU. Protein phosphatase PP1 is required for normal DNA methylation in Neurospora. Genes Dev. 2008;22: 3391-6.

205. Jeong MW, Kang TH, Kim W, Choi YH, Kim KT. Mitogenactivated protein kinase phosphatase 2 regulates histone $\mathrm{H} 3$ phosphorylation via interaction with vaccinia-related kinase 1 . Mol Biol Cell. 2013;24:373-84.

206. Sofueva S, Du L-L, Limbo O, Williams JS, Russell P. BRCT domain interactions with phospho-histone $\mathrm{H} 2 \mathrm{~A}$ target $\mathrm{Crb} 2$ to chromatin at double-strand breaks and maintain the DNA damage checkpoint. Mol Cell Biol. 2010;30:4732-43.

207. Jeyaprakash AA, Basquin C, Jayachandran U, Conti E. Structural basis for the recognition of phosphorylated histone $h 3$ by the survivin subunit of the chromosomal passenger complex. Structure. 2011;19:1625-34.

208. Kim JY, Banerjee T, Vinckevicius A, Luo Q, Parker JB, Baker $\mathrm{MR}$, et al. A role for WDR5 in integrating threonine 11 phosphorylation to lysine 4 methylation on histone $\mathrm{H} 3$ during androgen signaling and in prostate cancer. Mol Cell. 2014;54:613-25.

209. Di Lorenzo A, Bedford MT. Histone arginine methylation. FEBS Lett. 2011;585:2024-31.

210. Molina-Serrano D, Schiza V, Kirmizis A. Cross-talk among epigenetic modifications: lessons from histone arginine methylation. Biochem Soc Trans. 2013;41:751-9.

211. Gayatri S, Bedford MT. Readers of histone methylarginine marks Biochim Biophys Acta. 2014;1839:702-10.

212. Black JC, Van Rechem C, Whetstine JR. Histone lysine methylation dynamics: establishment, regulation, and biological impact. Mol Cell. 2012;48:491-507.

213. Greer EL, Shi Y. Histone methylation: a dynamic mark in health, disease and inheritance. Nat Rev Genet. 2012;13:343-57.

214. Liu C, Lu F, Cui X, Cao X. Histone methylation in higher plants. Annu Rev Plant Biol. 2010;61:395-420.

215. Fischle W, Tseng BS, Dormann HL, Ueberheide BM, Garcia BA, Shabanowitz J, et al. Regulation of HP1-chromatin binding by histone H3 methylation and phosphorylation. Nature. 2005;438: 1116-22.

216. Hirota T, Lipp JJ, Toh B-H, Peters J-M. Histone H3 serine 10 phosphorylation by Aurora B causes HP1 dissociation from heterochromatin. Nature. 2005;438:1176-80.

217. Gehani SS, Agrawal-Singh S, Dietrich N, Christophersen NS, Helin K, Hansen K. Polycomb group protein displacement and gene activation through MSK-dependent H3K27me3S28 phosphorylation. Mol Cell. 2010;39:886-900. The authors demonstrate that MSK1 phosphorylates H3K27me3 nucleosomes in promoters during retinoic acid stimulation, mitogen stimulation or serum starvation and the resulting $H 3 K 27$ me3/S28ph dual mark displaces PRC2 to activate polycomb-silenced genes in fibroblasts and neuronal cells. This study provides key molecular evidence demonstrating the relationship between $H 3 K 27$ me3 and H3S28ph.

218. Lau PNI, Cheung P. Histone code pathway involving H3 S28 phosphorylation and K27 acetylation activates transcription and antagonizes polycomb silencing. Proc Natl Acad Sci U S A. 2011;108:2801-6. This study uncovers the relationship between H3K27ac and MSK1-dependent H3S28 phosphorylation. The authors demonstrate that targeting MSK1 to $\alpha$-globin promoter results in a dual H3K27ac/S28ph mark and induces expression in non-erythroid cells.

219. Hershko A, Ciechanover A. The ubiquitin system. Annu Rev Biochem. 1998;67:425-79.

220. Peters JM, Harris, J R, Finle, D. Ubiquitin and the biology of the cell. 1998.

221. Pickart CM. Mechanisms underlying ubiquitination. Annu Rev Biochem. 2001;70:503-33.

222. Kerscher O, Felberbaum R, Hochstrasser M. Modification of proteins by ubiquitin and ubiquitin-like proteins. Annu Rev Cell Dev Biol. 2006;22:159-80.

223. Komander D, Rape M. The ubiquitin code. Annu Rev Biochem. 2012;81:203-29.

224. Husnjak K, Dikic I. Ubiquitin-binding proteins: decoders of ubiquitin-mediated cellular functions. Annu Rev Biochem. 2012;81:291-322.

225. Levinger L, Varshavsky A. Selective arrangement of ubiquitinated and D1 protein-containing nucleosomes within the Drosophila genome. Cell. 1982;28:375-85. 
226. Braun S, Madhani HD. Shaping the landscape: mechanistic consequences of ubiquitin modification of chromatin. EMBO Rep. 2012;13:619-30.

227. Sun ZW, Allis CD. Ubiquitination of histone $\mathrm{H} 2 \mathrm{~B}$ regulates $\mathrm{H} 3$ methylation and gene silencing in yeast. Nature. 2002;418:104-8.

228. $\mathrm{Ng} \mathrm{HH}, \mathrm{Xu} \mathrm{RM}$, Zhang Y, Struhl K. Ubiquitination of histone H2B by Rad6 is required for efficient Dot1-mediated methylation of histone H3 lysine 79. J Biol Chem. 2002;277:34655-7.

229. Fuchs G, Oren M. Writing and reading H2B monoubiquitylation. Biochim Biophys Acta. 2014;1839:694-701.

230. Fierz B, Chatterjee C, Mcginty RK, Bar-Dagan M, Raleigh DP, Muir TW. Histone H2B ubiquitylation disrupts local and higherorder chromatin compaction. Nat Chem Biol. 2011;7:113-9. This study elegantly uses in vitro methods to demonstrate a direct effect of $\mathrm{H} 2 \mathrm{Bub}$ on chromatin compaction.

231. Shema-Yaacoby E, Nikolov M, Haj-Yahya M, Siman P, Allemand E, Yamaguchi Y, et al. Systematic identification of proteins binding to chromatin-embedded ubiquitylated $\mathrm{H} 2 \mathrm{~B}$ reveals recruitment of SWI/SNF to regulate transcription. Cell Rep. 2013;4: $601-8$.

232. McGinty RK, Kim J, Chatterjee C, Roeder RG, Muir TW. Chemically ubiquitylated histone H2B stimulates hDot1Lmediated intranucleosomal methylation. Nature. 2008;453:812-6.

233. Kim J, Kim JA, McGinty RK, Nguyen UT, Muir TW, Allis CD, et al. The n-SET domain of Set1 regulates H2B ubiquitylationdependent H3K4 methylation. Mol Cell. 2013;49:1121-33.

234. Lan L, Nakajima S, Kapetanaki MG, Hsieh CL, Fagerburg M, Thickman K, et al. Monoubiquitinated histone H2A destabilizes photolesion-containing nucleosomes with concomitant release of UV-damaged DNA-binding protein E3 ligase. J Biol Chem. 2012;287:12036-49.

235. Huen MS, Grant R, Manke I, Minn K, Yu X, Yaffe MB, et al. RNF8 transduces the DNA-damage signal via histone ubiquitylation and checkpoint protein assembly. Cell. 2007;131: 901-14.

236. Mailand N, Bekker-Jensen S, Faustrup H, Melander F, Bartek J, Lukas C, et al. RNF8 ubiquitylates histones at DNA double-strand breaks and promotes assembly of repair proteins. Cell. 2007;131: 887-900.

237. Doil C, Mailand N, Bekker-Jensen S, Menard P, Larsen DH, Pepperkok R, et al. RNF168 binds and amplifies ubiquitin conjugates on damaged chromosomes to allow accumulation of repair proteins. Cell. 2009;136:435-46.

238. Thakar A, Parvin J, Zlatanova J. BRCA1/BARD1 E3 ubiquitin ligase can modify histones $\mathrm{H} 2 \mathrm{~A}$ and $\mathrm{H} 2 \mathrm{~B}$ in the nucleosome particle. J Biomol Struct Dyn. 2010;27:399-406.

239. Kalb R, Mallery DL, Larkin C, Huang JT, Hiom K. BRCA1 is a histone-H2A-specific ubiquitin ligase. Cell Rep. 2014;8:999 1005. This study reports that the tumour suppressor functions of BRCA1 are mediated through its H2AK119ub activity.

240. Fradet-Turcotte A, Canny MD, Escribano-Díaz C, Orthwein A, Leung CCY, Huang $\mathrm{H}$, et al. 53BP1 is a reader of the DNAdamage-induced H2A Lys 15 ubiquitin mark. Nature. 2014;498: 50-4. This paper reports H2AK13-15 ubiquitination as a novel mark that is established by RNF168 and read by p53 in DNA repair pathways.

241. Zhu Q, Pao GM, Huynh AM, Suh H, Tonnu N, Nederlof PM, et al. BRCA1 tumour suppression occurs via heterochromatin-mediated silencing. Nature. 2011;477:179-84

242. Simon JA, Kingston RE. Mechanisms of polycomb gene silencing: knowns and unknowns. Nat Rev Mol Cell Biol. 2009;10: 697-708.

243. Schwartz YB, Pirrotta V. Polycomb silencing mechanisms and the management of genomic programmes. Nat Rev Genet. 2007;8:9-22.
244. Wang L, Brown JL, Cao R, Zhang Y, Kassis JA, Jones RS. Hierarchical recruitment of polycomb group silencing complexes. Mol Cell. 2004;14:637-46.

245. Dellino GI, Schwartz YB, Farkas G, McCabe D, Elgin SC, Pirrotta V. Polycomb silencing blocks transcription initiation. Mol Cell. 2004;13:887-93.

246. Cao R, Wang L, Wang H, Xia L, Erdjument-Bromage H, Tempst $\mathrm{P}$, et al. Role of histone H3 lysine 27 methylation in polycombgroup silencing. Science. 2002;298:1039-43.

247. Endoh M, Endo TA, Endoh T, Isono K, Sharif J, Ohara O, et al. Histone H2A mono-ubiquitination is a crucial step to mediate PRC1-dependent repression of developmental genes to maintain ES cell identity. PLoS Genet. 2012;8:e1002774. This paper and the next four papers present a novel understanding of the polycomb silencing pathway, they demonstrate that H2AK119ub can drive H3K27me. The authors show that polycomb-mediated repression in ES cells requires H2AK119ub and additional mechanisms.

248. Kalb R, Latwiel S, Baymaz HI, Jansen PW, Muller CW, Vermeulen M, et al. Histone H2A monoubiquitination promotes histone $\mathrm{H} 3$ methylation in polycomb repression. Nat Struct Mol Biol. 2014;21:569-71. The authors find that H2AK119ub established by PRC1 is read by Jarid 2 and Aebp 2 components of the PRC2 complex that eventually establishes H3K27me3.

249. Tavares L, Dimitrova E, Oxley D, Webster J, Poot R, Demmers J, et al. RYBP-PRC1 complexes mediate $\mathrm{H} 2 \mathrm{~A}$ ubiquitylation at polycomb target sites independently of PRC2 and H3K27me3. Cell. 2012;148:664-78. This study reports that PRC1 complex is recruited to polycomb target sites in the absence of a catalytic PRC2 complex.

250. Cooper S, Dienstbier M, Hassan R, Schermelleh L, Sharif J, Blackledge NP, et al. Targeting polycomb to pericentric heterochromatin in embryonic stem cells reveals a role for $\mathrm{H} 2 \mathrm{AK} 119 \mathrm{u} 1$ in PRC2 recruitment. Cell Rep. 2014;7:1456-70. This study reports the key finding that the density of unmethylated CpGs helps determine the localization of PRC1 and PRC2 in ES cells. Moreover, PRC1 mediated H2AK119ub is sufficient to recruit PRC2 to polycomb targets.

251. Blackledge NP, Farcas AM, Kondo T, King HW, McGouran JF, Hanssen LLP, et al. Variant PRC1 complex-dependent H2A ubiquitylation drives PRC2 recruitment and polycomb domain formation. Cell. 2014;157:1445-59. This study finds that the variant PCGF1/PRC1complex is targeted to unmethylated $C p G$ islands by KDM2B during embryonic development and PRC1 then establishes H2AK119ub to recruit PRC2 that sets up H3K27me3.

252. Yuan Z-F, Arnaudo AM, Garcia BA. Mass spectrometric analysis of histone proteoforms. Annu Rev Anal Chem. 2014;7:113-28.

253. Han Y, Garcia BA. Combining genomic and proteomic approaches for epigenetics research. Epigenomics. 2013;5:439-52.

254. Karch KR, Denizio JE, Black BE, Garcia BA. Identification and interrogation of combinatorial histone modifications. Front Genet. 2013;4:264.

255. Tan M, Luo H, Lee S, Jin F, Yang JS, Montellier E, et al. Identification of 67 histone marks and histone lysine crotonylation as a new type of histone modification. Cell. 2011;146:1016-28.

256. Unoki M, Masuda A, Dohmae N, Arita K, Yoshimatsu M, Iwai Y, et al. Lysyl 5-hydroxylation, a novel histone modification, by jumonji domain containing 6 (JMJD6). J Biol Chem. 2013;288: 6053-62.

257. Tessarz P, Santos-Rosa H, Robson SC, Sylvestersen KB, Nelson CJ, Nielsen ML, et al. Glutamine methylation in histone $\mathrm{H} 2 \mathrm{~A}$ is an RNA-polymerase-I-dedicated modification. Nature. 2015;505: 564-8.

258. Chen X, Xiong J, Xu M, Chen S, Zhu B. Symmetrical modification within a nucleosome is not required globally for histone lysine 
methylation. EMBO Rep. 2011;12:244-51. This study demonstrates that asymmetrically modified nucleosomes can exist in vivo.

259. Voigt P, LeRoy G, Drury I, William J, Zee BM, Son J, et al. Asymmetrically modified nucleosomes. Cell. 2012;151:181-93. This paper elegantly develops the concept of asymmetric nucleosomes and presents evidence supporting the view that the bivalent distribution of histone methylation (H3K4me/H3K27me) may result from these two modifications being present on two different $H 3$ tails of the same nucleosome. They show that PRC2 can methylate H3K27 when the nucleosome substrate has either no or asymmetric H3K4me or H3K36me. The authors also demonstrate asymmetry at other sites of methylation on $\mathrm{H} 3$ and $\mathrm{H} 4$.

260. Nelson CJ, Santos-Rosa H, Kouzarides T. Proline isomerization of histone $\mathrm{H} 3$ regulates lysine methylation and gene expression. Cell. 2006;126:905-16.

261. Dilworth D, Gudavicius G, Leung A, Nelson CJ. The roles of peptidyl-proline isomerases in gene regulation. Biochem Cell Biol = Biochimie et biologie cellulaire. 2012;90:55-69.

262. Raghuram N, Strickfaden H, McDonald D, Williams K, Fang $\mathrm{H}$, Mizzen $\mathrm{C}$, et al. Pin1 promotes histone $\mathrm{H} 1$ dephosphorylation and stabilizes its binding to chromatin. J Cell Biol. 2013;203:57-71.

263. Duncan EM, Muratore-Schroeder TL, Cook RG, Garcia BA, Shabanowitz J, Hunt DF, et al. Cathepsin L proteolytically processes histone $\mathrm{H} 3$ during mouse embryonic stem cell differentiation. Cell. 2008;135:284-94.

264. Santos-Rosa H, Kirmizis A, Nelson C, Bartke T, Saksouk N, Cote $\mathrm{J}$, et al. Histone $\mathrm{H} 3$ tail clipping regulates gene expression. Nat Struct Mol Biol. 2008;16:17-22.

265. Xue Y, Vashisht AA, Tan Y, Su T, Wohlschlegel JA. PRB1 is required for clipping of the histone $\mathrm{H} 3 \mathrm{~N}$ terminal tail in Saccharomyces cerevisiae. PLoS ONE. 2014;9:e90496.

266. Suto RK, Clarkson MJ, Tremethick DJ, Luger K. Crystal structure of a nucleosome core particle containing the variant histone H2A.Z. Nat Struct Biol. 2000;7:1121-4.

267. Weber CM, Henikoff JG, Henikoff S. H2A.Z nucleosomes enriched over active genes are homotypic. Nat Struct Mol Biol. 2010;17:1500-7. This study presents the genome-wide distribution of H2A.Z in Drosophila and demonstrates that 5' region of active genes are enriched for homotypic H2A.Z nucleosomes since they are more stable to RNA Pol II-mediated disruption as compared to heterotypic nucleosomes (H2A/H2A.Z).

268. Nekrasov M, Amrichova J, Parker BJ, Soboleva TA, Jack C, Williams R, et al. Histone H2A.Z inheritance during the cell cycle and its impact on promoter organization and dynamics. Nat Struct Mol Biol. 2012;19:1076-83.

269. van Rossum B, Fischle W, Selenko P. Asymmetrically modified nucleosomes expand the histone code. Nat Struct Mol Biol. 2012;19:1064-6. 